(A) Check for updates

Cite this: Org. Biomol. Chem., 2018, 16,6206

Received 22nd April 2018,

Accepted 23rd July 2018

DOI: 10.1039/c8ob00944a

rsc.li/obc

\section{Molecular tweezers with a rotationally restricted linker and freely rotating porphyrin moieties $\uparrow$}

\author{
Rhys B. Murphy, ID +a Duc-Truc Pham, id b Jonathan M. White, id c \\ Stephen F. Lincoln ${ }^{b}{ }^{b}$ and Martin R. Johnston (iD *a
}

\section{Introduction}

The guest complexation behavior of molecular tweezers is heavily dependent on the crucial role played by the linker in providing preorganisation. ${ }^{1-3}$ In general terms, it is reported that conformationally rigid linkers afford larger association constants than systems with conformationally flexible linkers, ${ }^{4,5}$ as well as offering substrate selectivity provided that the dimensions of the tweezer cavity are suited to the substrate. ${ }^{4}$ Conformationally flexible linkers allow complexation of substrates of different sizes and shapes, ${ }^{4,6}$ and these systems may suffer from poor selectivity. ${ }^{7}$ However, it can be advantageous to balance the degree of host preorganisation and rigidity with conformational flexibility, as demonstrated by several notable examples:

- a metalloporphyrin host which increases the rate of a hetero-Diels-Alder reaction, ${ }^{8}$

- disulfide-linked bis(cyclopeptides) which display high affinity and selectivity for the sulfate anion in aqueous solution, ${ }^{9}$

\footnotetext{
${ }^{a}$ Flinders Centre for NanoScale Science and Technology, College of Science and Engineering, Flinders University, Bedford Park, Adelaide, Australia.

E-mail: martin.johnston@flinders.edu.au

${ }^{b}$ Department of Chemistry, The University of Adelaide, Adelaide, Australia ${ }^{c}$ School of Chemistry, The University of Melbourne, Melbourne, Australia

$\dagger$ Electronic supplementary information (ESI) available: NMR, UV/Vis, MS, X-ray, complexation models, statistical analysis, effective molarity. CCDC 1526930 and 1526931. For ESI and crystallographic data in CIF or other electronic format see DOI: $10.1039 / \mathrm{c} 80 \mathrm{~b} 00944 \mathrm{a}$

¥Present address: Australian Nuclear Science and Technology Organisation, Locked Bag 2001, Kirrawee DC, NSW 2232, Australia.
}

- the comparison of the effective molarities (EM) for a large number of porphyrin-pyridine complexes with different torsional degrees of freedom, ${ }^{10}$

- and the use of flexible cyclodextrins to template porphyrin nanorings. ${ }^{11}$

In a series of bis-porphyrin hosts each containing different linker structures, ${ }^{12-14}$ it has been observed that large association constants can be obtained for architectures containing either conformationally flexible, restricted, or more rigidly constrained linkers, and that the linker need only confer the system with moderate preorganization.§ Additional evidence for this is provided by both our recent work ${ }^{15}$ and a variety of porphyrin host-guest systems with varying degrees of preorganisation, ${ }^{6-8,12,13,16-27}$ including those which allow defined changes in interporphyrin distance. Further, there continues to be an active interest to explore linker conformational rigidity/flexibility in porphyrin tweezers. ${ }^{28,29}$

Biological receptors, which are dynamic and far from rigid, possess comparatively larger association constants compared to those of most artificial receptors. ${ }^{5,9}$ This has led to discussion that adopting a rigid-only approach to host design which relies solely on covalent linkages to establish geometry could limit the scope of artificial receptors. ${ }^{5,9}$

We have previously described the host-guest chemistry of bis-porphyrin tweezer $1,{ }^{15}$ which forms a strong $1 \cdot \mathrm{DABCO}$ bis-porphyrin:DABCO complex with the aliphatic diamino ligand 1,4-diazabicyclo[2.2.2] octane (DABCO), and more recently reported the synthesis of a tetra-porphyrin tweezer 2

$\S$ Although there are examples where conformationally flexible linkers are insufficiently preorganised and small association constants are obtained. ${ }^{13,14}$ 
with two cooperative binding $\operatorname{sites}^{30}$ (Fig. 1). In these systems, host preorganisation was achieved by using a bridged polycyclic linker. The favourable properties of fused [n]polynorbornyl scaffolds in molecular receptors, particularly with respect to host preorganisation, are reported in the literature by a number of research groups including those of Warrener and Butler, ${ }^{7,31-39}$ Paddon-Row, ${ }^{40-43}$ Johnston, ${ }^{19,44-46}$ Pfeffer, ${ }^{47-53}$ Clever, ${ }^{47,50,54}$ and Margetić. ${ }^{55-58}$

Importantly, tweezers $\mathbf{1}$ and $\mathbf{2}$ share a freely rotating phenyl diimide core inserted within the otherwise rigid polycyclic linker, a feature which allows unhindered adjustment of the interporphyrin distance, to potentially allow the binding of guests of different lengths. However, because all conformations are readily accessible, the possibility of $\mathbf{1}$ assuming an anti-conformation arises, thereby decreasing the proportion of the syn-conformation and the formation of $s y n-1$ bis-porphyrin:guest complexes. This possibility is also inherent in the design of other molecular tweezers in the literature (for several examples see ref. 24 and 59-63).

To investigate the role of the phenyl core on the host-guest behaviour of molecular architectures 1 and 2, we designed restricted rotation tweezer 3 (Fig. 2). Tweezer 3 maintains the rigid bridged polycyclic scaffold but contains a phenyl diimide core with sterically bulky methyl substituents (dotted box, Fig. 2). These methyl substituents drastically increase the energy barrier to rotation about the phenyl diimide core and afford non-interconvertible syn-3a and anti-3b conformations, providing the opportunity to study the host-guest complexation of each conformation independently.

This manuscript reports on the synthesis, isolation and characterisation of the $s y n-\mathbf{3 a}$ and anti-3b conformers. Further,
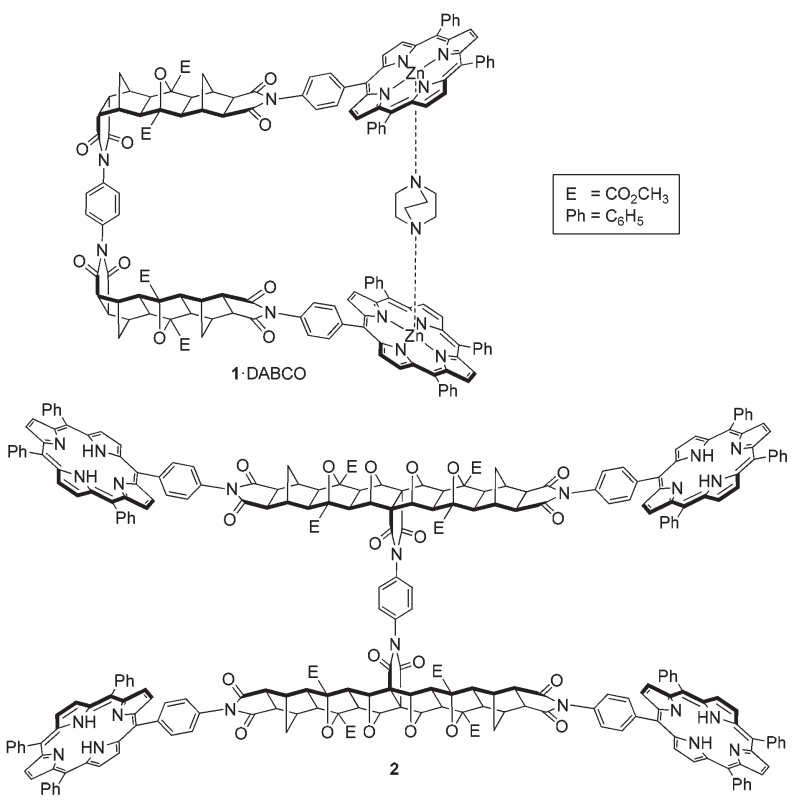

Fig. 1 Previously described tweezer systems with a freely rotating phenyl diimide core; single binding site tweezer $1^{15}$ (shown as complex 1.DABCO), and two binding site tweezer $2 .^{30}$

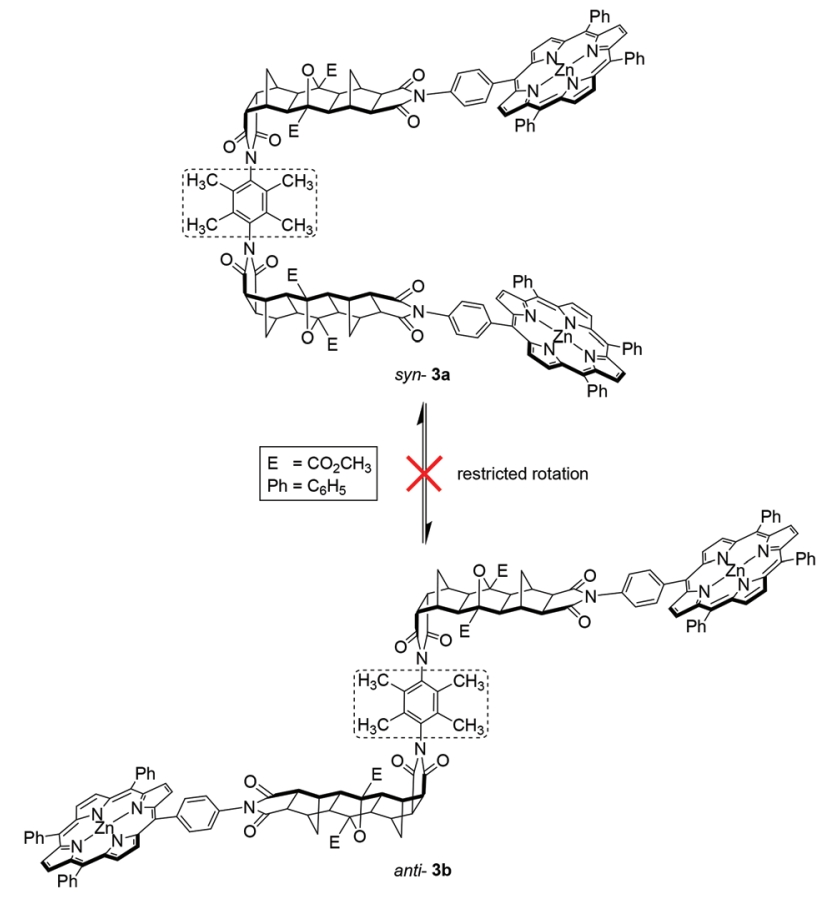

Fig. 2 Restricted rotation single binding site tweezer 3, where noninterconvertible syn-3a and anti-3b conformations arise due to a sterically bulky 2,3,5,6-tetramethylphenyl diimide core.

their complexation with DABCO was studied by UV-Vis and NMR spectroscopy and the resulting data fitted to various models of stoichiometry using non-linear least squares analysis.

\section{Results and discussion}

\section{Synthesis}

The synthesis of tweezer $\mathbf{3}$ was undertaken in a similar manner to tweezer $1^{15}$ involving the condensation of endoMitsudo anhydride $\mathbf{4}^{15,55}$ with 2,3,5,6-tetramethyl- $p$ phenylenediamine $\mathbf{5}$, followed by ring closing to form imides 6a and $\mathbf{6 b}$ (Scheme 1).

The ${ }^{1} \mathrm{H}$ NMR spectrum of the reaction mixture (not shown) revealed two pairs of signals for the methyl phenyl substituent proton resonances. This was attributed to the two different linker conformations of syn-6a and anti-6b. The mixture showed a slight deviation from statistical, in an approximately $60: 40$ ratio based on the relative integration between the two pairs of signals within the mixture. $\uparrow$

To provide experimental evidence for separate syn-6a and anti-6b conformers, a small sample was separated by using a combination of column chromatography and selective recrystallisation. The partial ${ }^{1} \mathrm{H}$ NMR spectra highlighting the

IThis apparent non-statistical mixture could result from differential solubility of the syn-6a and anti-6b conformations in the precipitate and filtrate after the reaction, however this has not been investigated further. 

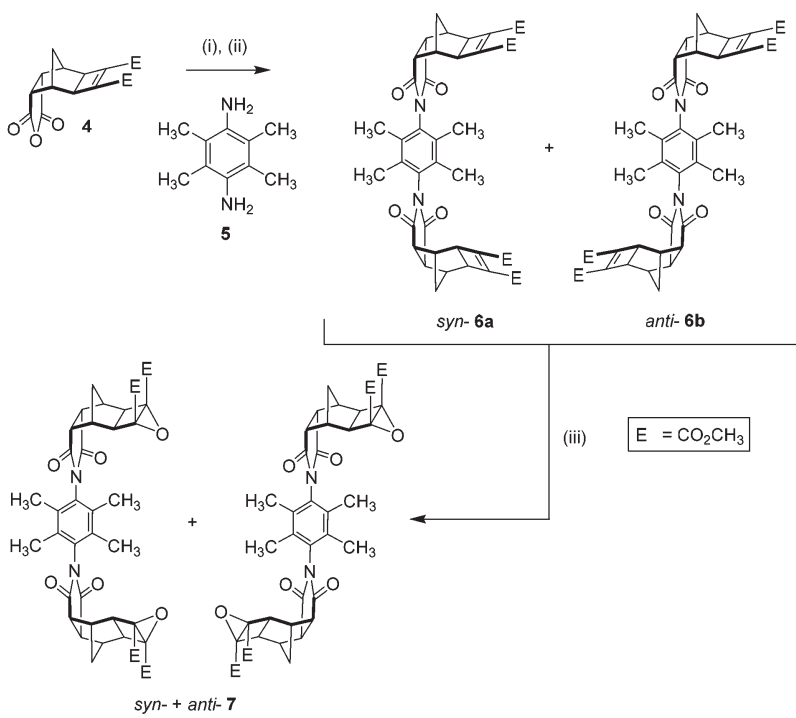

Scheme 1 Synthesis of the restricted rotation linker. (i) 2,3,5,6Tetramethyl- $p$-phenylenediamine 5 (0.5 eq.), dry DMSO, Ar deoxygenated, $80^{\circ} \mathrm{C}, 1$ day; (ii) $\mathrm{NaOAc} / \mathrm{Ac}_{2} \mathrm{O}, 80^{\circ} \mathrm{C}, 1$ day, $72 \%$ (as a mixture of syn-6a + anti-6b); (iii) anhydrous $t \mathrm{BuOOH}$ in toluene (3.3 M, 2.5-5 eq.), dry $\mathrm{CH}_{2} \mathrm{Cl}_{2}, 0^{\circ} \mathrm{C}, 10 \mathrm{~min}$, $\mathrm{BuOK}$ (1-2 eq.), room temp., 3.5-7 h, 51\%.

methyl resonances are shown in Fig. 3 (full ${ }^{1} \mathrm{H}$ NMR spectra S1 and $\mathrm{S} 3 \dagger$ ). In either conformation, the two methyl groups are non-equivalent resulting in two resonances. Additionally, the syn-6a and anti-6b conformations have different ${ }^{13} \mathrm{C}$ NMR spectra (S2 and S4†); with pairs of non-equivalent methyl and phenyl carbon resonances evident.

The mixture of syn-6a and anti-6b was subsequently epoxidised under standard conditions for electron deficient alkenes
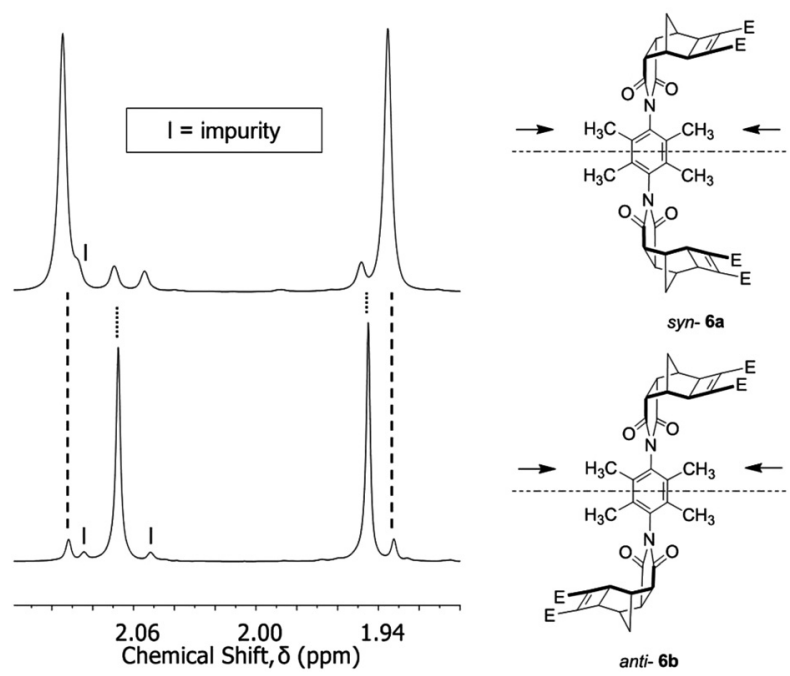

Fig. 3 Selected region of the ${ }^{1} \mathrm{H}$ NMR spectrum of the syn-6a and anti$6 \mathrm{~b}$ restricted rotation linker (absolute conformation unassigned), showing the different chemical environments of the methyl groups. Each sample contained traces of the other conformation and these are shown by the dotted lines. Impurity is marked by the letter I. Spectra recorded at $600 \mathrm{MHz}$ in $\mathrm{CDCl}_{3}$. $(t \mathrm{BuOOH} / \mathrm{tBuOK}),{ }^{33,35}$ to afford bis-epoxide 7 (Scheme 1). The bis-epoxide mixture 7 was subsequently appended with exoporphyrin receptors $\mathbf{8}^{15}$ via the alkene plus cyclobutane epoxide (ACE) reaction (Scheme 2) in a sealed tube. ${ }^{64}$ Overall, the reaction proceeded in a $23 \%$ yield, which upon NMR analysis was shown to exist as $10 \%$ syn-9a and $13 \%$ anti-9b conformations. The syn- and anti-assignment was achieved using ${ }^{1} \mathrm{H}$ NMR of the zinc metallated porphyrin derivatives, $\mathbf{3 a}$ and $\mathbf{3 b}$ respectively (vide infra).

The ${ }^{1} \mathrm{H}$ NMR spectra of the syn-9a and anti-9b mixture contained several features characteristic of ACE-coupled reactions, including a small downfield shift for the methyl ester resonance compared to that of the epoxide $7,{ }^{65}$ along with the disappearance of the norbornyl proton resonance from the exoporphyrin receptor 8 at $6.45 \mathrm{ppm}$. The ${ }^{13} \mathrm{C}$ NMR spectrum contained a resonance at $90 \mathrm{ppm}$, similar to other polycyclic
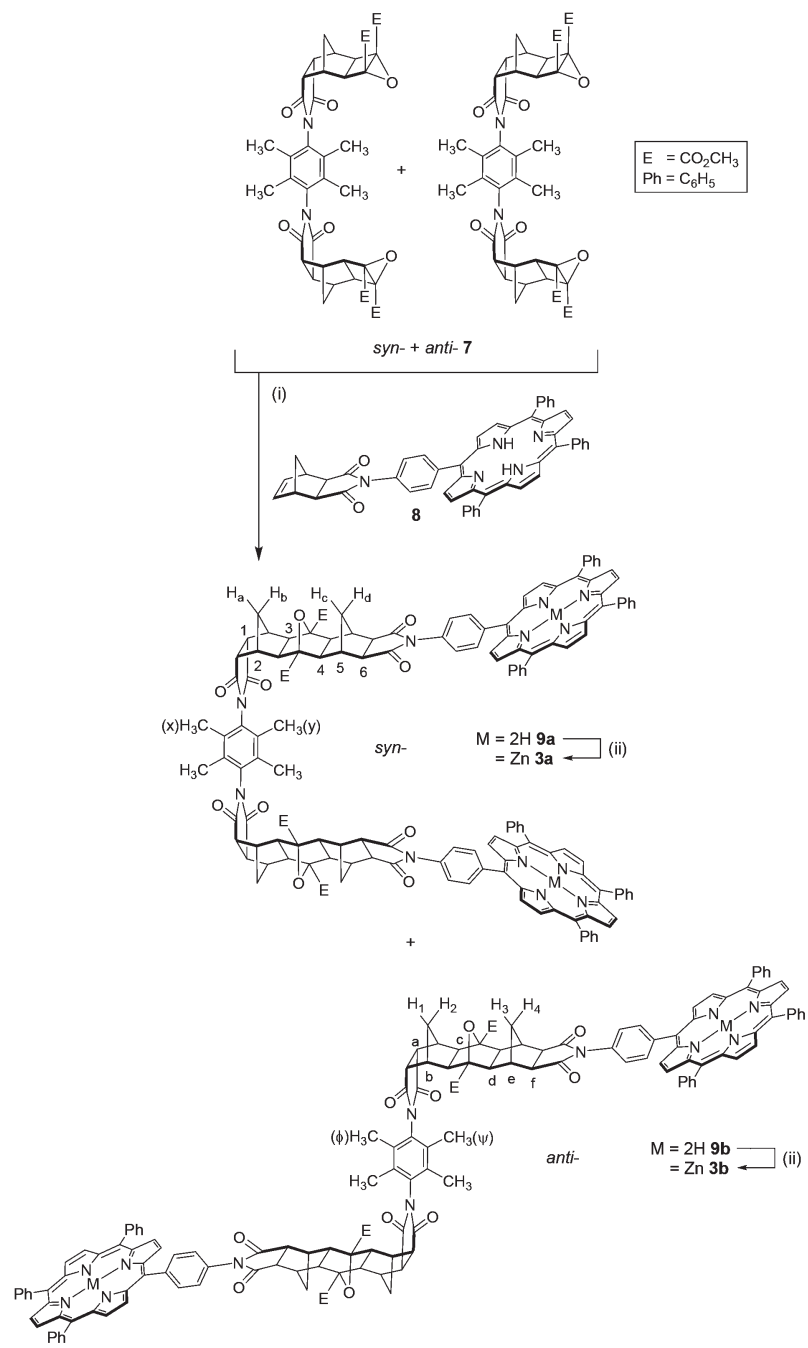

Scheme 2 Synthesis of tweezer 3, syn-3a and anti-3b. (i) exoPorphyrin receptor 8 (2 eq.), dry THF, sealed tube, $160{ }^{\circ} \mathrm{C}, 24 \mathrm{~h}, 23 \%$ (10\% syn-3a $+13 \%$ anti-3b); (ii) $\mathrm{Zn}(\mathrm{OAc})_{2} / \mathrm{MeOH} / \mathrm{CHCl}_{3}$, reflux, $1-2 \mathrm{~h}$, $79-89 \%$. 
systems ${ }^{38}$ which is assigned to the bridgehead carbon atoms in the newly formed 7-oxanorbornane. ${ }^{38}$

Relative integration of the two inner pyrrole proton resonances in the ${ }^{1} \mathrm{H}$ NMR spectrum of the crude mixture suggested the ratio of syn-:anti- was approximately $43: 57$. While separation by column chromatography yielded the anti9b conformation completely free of syn-9a, the syn-9a conformation contained approximately $25 \%$ residual anti-9b. In an effort to conserve limited product, further purification to remove anti-9b from syn-9a was carried out post-zinc(II) metallation, as syn-3a. The identity of the partially purified freebase syn-9a and anti-9b were confirmed by using accurate MS (S9), $\uparrow$ ESI-TOF, for two samples containing different ratios of syn-9a and anti-9b (sample $1[\mathrm{M}+2 \mathrm{H}]^{2+}$ found: 1162.4267 , calc: 1162.4260; sample $2[\mathrm{M}+2 \mathrm{Na}]^{2+}$ found: 1184.4110 , calc: 1184.4079).

The freebase syn-9a and anti-9b mixture and pure anti-9b were metallated with zinc(II) under standard conditions, ${ }^{66}$ giving syn-3a and anti-3b respectively (Scheme 2). Zinc(II) metallation was characterised by loss of the porphyrin inner pyrrole proton resonance at -2.80 (anti-) and -2.84 (syn-) in the ${ }^{1} \mathrm{H}$ NMR spectrum. Several slow recrystallisations enabled the zinc(II) syn-3a conformation to be purified completely free of anti-3b. HRMS (MALDI-TOF) of syn-3a and anti-3b further confirmed zinc(II) metallation. MALDI-TOF of porphyrin compounds is reported to afford the radical molecular ion, $[\mathrm{M}]^{\circ+}$, without the uptake of $\mathrm{H}^{+}$or $\mathrm{Na}^{+}{ }^{67}$ The monoisotopic mass for $[\mathrm{M}]^{\cdot+}$ was found to be 2446.694 for $s y n-3 a$ and 2446.6770 for anti-3b, which compares well with the calculated value of $2446.6644\left(5,10,15,20\right.$-tetraphenylporphin, $\mathrm{H}_{2} \mathrm{TPP}$, was used for internal calibration). In addition, the profiles of the experimental and theoretical MS spectra are in excellent agreement $(\mathrm{S} 15 \dagger)$.

In the ${ }^{1} \mathrm{H}$ NMR spectrum for each adduct (syn-3a, S10, $\dagger$ anti-3b, S13 $\dagger$ ), ten polycyclic resonances occur as expected (excluding the methyl ester and two methyl phenyl substituent resonances); six singlets and four doublets. The doublets arise from two pairs of non-equivalent methylene bridge protons, $\mathrm{H}_{\mathrm{a}} / \mathrm{H}_{\mathrm{b}}$ and $\mathrm{H}_{\mathrm{c}} / \mathrm{H}_{\mathrm{d}}$ in the case of syn-3a, and $\mathrm{H}_{1} / \mathrm{H}_{2}$ and $\mathrm{H}_{3} / \mathrm{H}_{4}$ in the case of anti-3b (Scheme 2). These pairs (e.g. $\mathrm{H}_{\mathrm{a} / \mathrm{b}}$ and $\mathrm{H}_{\mathrm{c} / \mathrm{d}}$, or $\mathrm{H}_{1 / 2}$ and $\mathrm{H}_{3 / 4}$ ) appear at significantly different chemical shifts, characteristic of steric compression by oxygen in these systems, ${ }^{55}$ and confirms the formation of a linear ACE product. ${ }^{55}$ These resonances occur at chemical shifts of 2.77/1.43 ppm and 2.49/1.13 ppm for syn3a and 2.77/1.42 ppm and 2.54/1.22 ppm for anti-3b. The six signals correspond with the number of unique proton chemical environments along the polycyclic scaffold (marked 1-6 for syn-3a and a-f for anti-3b in Scheme 2). In addition, a pair of methyl phenyl substituent resonances for the linker core are observed at chemical shifts of 2.31 and $2.00 \mathrm{ppm}$ for syn-3a and 2.28 and $2.04 \mathrm{ppm}$ for anti-3b (marked $\mathrm{x}$ and y for syn-3a, $\Phi$ and $\Psi$ for anti-3b in Scheme 2, absolute assignment not determined). This is in line with similar observations for the syn-6a and anti-6b linkers described in Fig. 3.
The different aromatic regions of the ${ }^{1} \mathrm{H}$ NMR spectra of $s y n-3 \mathbf{a}$ and anti-3b are shown in Fig. 4. The splitting of the porphyrin resonances, in particular the $\beta$-pyrrole resonances, and the differences in integration of the meso-phenyl resonances between the two conformations indicates facial differentiation of the porphyrin macrocycles as a result of the close proximity of the opposing ring in the syn-conformation. For the anti-conformation, no major splitting of the porphyrin resonances was observed and the integrations are typical of compounds of the type mono-porphyrin $10^{15}$ (structure given in Table 1), presumably as the porphyrins cannot be positioned cofacially (unless intermolecular aggregation occurs). Additionally, the syn-conformation porphyrin resonances are shielded relative to the anti-, further demonstrating the effect of the adjacent $\pi$ systems in the syn-conformation.

For the syn-3a tweezer, several of the porphyrin meso-phenyl ${ }^{1} \mathrm{H}$ NMR resonances are broadened while others appear sharp. Furthermore, the ${ }^{1} \mathrm{H}$ NMR spectrum was highly concentration dependent $(\mathrm{S} 12(\mathrm{a}) \dagger)$, with significant resonance shifts observed for porphyrin and polycyclic resonances $(\Delta \delta=$ 0.3-0.7 ppm for samples more and less concentrated than $3.5 \mathrm{mM}$ ). Additional resonance shifts are observed between $+20{ }^{\circ} \mathrm{C}$ and $-50{ }^{\circ} \mathrm{C}(\mathrm{S} 12(\mathrm{~b}) \dagger)$ Taken together, these data suggest that the syn-tweezer is undergoing dynamic conformational changes (but not to anti-) on the NMR timescale,

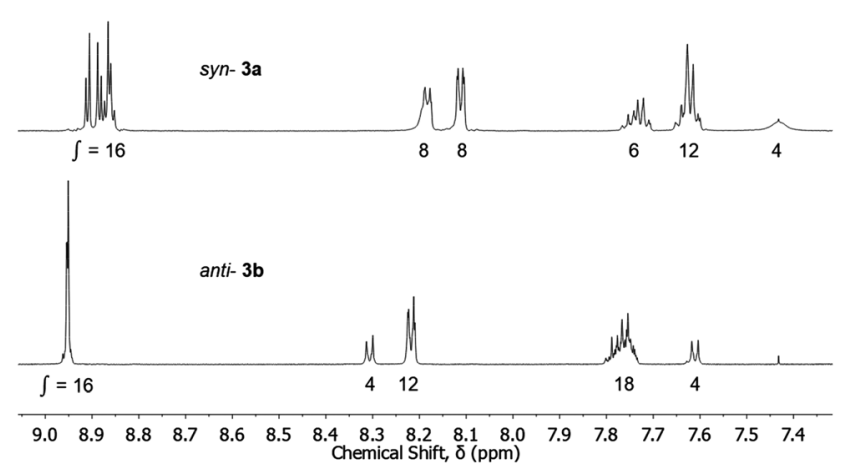

Fig. 4 Partial ${ }^{1} \mathrm{H}$ NMR (aromatic region) of the zinc(॥) metallated syn-3a and anti-3b restricted rotation tweezers. Spectra recorded at $600 \mathrm{MHz}$ in $\mathrm{CDCl}_{3}$.

Table 1 Summary of UV/Vis data in chloroform comparing syn-3a and anti-3b with mono-porphyrin 10 and tweezer 1

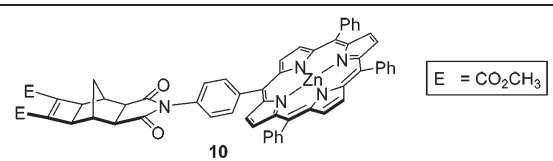

\begin{tabular}{lllrr}
\hline Species & $\begin{array}{l}\text { Zinc(II) } \\
\text { mono-porphyrin 10 }\end{array}$ & $\begin{array}{l}\text { Zinc(II) freely } \\
\text { rotating 1 }\end{array}$ & $\begin{array}{l}\text { Zinc(II) } \\
\text { syn-3a }\end{array}$ & $\begin{array}{l}\text { Zinc(II) } \\
\text { anti-3b }\end{array}$ \\
\hline$\lambda_{\max }(\mathrm{nm})$ & 419.3 & 419.5 & 418.4 & 419.3 \\
${\text { Width }(\mathrm{nm})^{a}}^{9}$ & 9.9 & 11.0 & 11.5 & 10.1 \\
${ }^{a}$ Peak bandwidth measured at half height. & &
\end{tabular}


and/or changes to intermolecular aggregation influenced by concentration and temperature, however this has not been investigated further.

For the zinc(II) anti-3b adduct, there are only minor $(<0.1 \mathrm{ppm})$ shifts in the spectrum at $-50{ }^{\circ} \mathrm{C}$ compared to room temperature. Concentration dependence of the ${ }^{1} \mathrm{H}$ NMR could not be established for anti-3b due to poor solubility at concentrations greater than $0.85 \mathrm{mM}$.

The UV/Vis spectra of the zinc(II) metallated syn-3a and anti3b adducts supported our conformational assignment. Zinc(II) anti-3b and zinc(II) mono-porphyrin $\mathbf{1 0}^{15} \|$ display very similar Soret maxima and peak bandwidths at half height (Table 1). The absence of exciton coupling interactions supports the assignment of the anti-conformation, ${ }^{59}$ where the bis-porphyrins are not positioned cofacially. Conversely, the Soret maxima of the zinc(II) syn-3a tweezer is blue shifted by $1 \mathrm{~nm}$ relative to the zinc(II) mono-porphyrin 10, and has a slightly larger peak bandwidth at half height than the zinc(II) freely rotating tweezer 1 (Table 1). Although the blue shift and broadening of the Soret band are both small, this could indicate weak exciton coupling interactions ${ }^{19,22,59,68-72}$ between the porphyrins in the syn-3a adduct. The weakness of the exciton coupling in the syn-3a adduct suggests that the bis-porphyrins are not fixed in a cofacial orientation, and that the porphyrin units are able to undergo rotation either about the meso-phenyl linking the porphyrin to the scaffold, and/or the two porphyrin arms can undergo restricted rotation about the diimide core.

\section{2,3,5,6-Tetramethylphenyl diimide as the linker}

Restricted rotation has been reported for $N$-phenyl imide derivatives with ortho-substituents other than hydrogen. ${ }^{73-83,94}$ As the size of this substituent increases, the energy barrier to rotation increases due to steric repulsion with the oxygen atom of the imide. ${ }^{84-86}$ In addition, the angle between the substituted phenyl and imide rings increases towards perpendicular to minimise this steric interaction. ${ }^{84,85,87,88}$ This comes at the expense of resonance delocalisation and conjugation favoured in the planar conformation ${ }^{89}$.** $^{*}$

NMR studies for mono-ortho-methyl substituted $N$-phenyl imide derivatives ${ }^{73,74}$ report a mixture of rotational isomers at ambient conditions and which undergo thermally activated bond rotation. No interconversion between syn-3a and anti-3b was observed for our fully substituted 2,3,5,6-tetramethylphenyl 1,4-diimide under the conditions examined; the systems are both stable to interconversion at room temperature over the duration of NMR experiments, while the ${ }^{1} \mathrm{H}$ NMR spectrum of the pure anti-3b adduct after microwave irradiation at $95{ }^{\circ} \mathrm{C}$ for 15 minutes $(300 \mathrm{~W}, 50 \mathrm{psi})$, or sonication at $30{ }^{\circ} \mathrm{C}$ for 15 minutes, showed no detectable interconversion from anti-3b to syn-3a (higher temperatures and longer times were not explored). However, a range of intermediate

|l Compound 10 was used due to the poor solubility of the zinc(II) metallated adduct of exo-porphyrin receptor $\mathbf{8}$ in chloroform.

** Ref. 89 relates to anilide derivatives rather than imides, however, the principle of balancing steric and electronic factors is the same here. conformations are envisaged to be energetically accessible within each of syn-3a and anti-3b, and would allow for some adjustment of the interporphyrin distance in the presence of guest.

Furthermore, in the course of this work, we examined several variations of linker $6,{ }^{90}$ most notably the exo-analogues 11 (Fig. 5). During synthesis of 11, the crude filtrate and crude precipitate of the reaction mixture contained mainly the opposite conformational isomer respectively (different solubility). Conveniently, slow evaporation of acetonitrile solutions of the precipitate and filtrate afforded crystals suitable for X-ray diffraction measurements. The crystal structures are shown in Fig. 6.

While crystal packing forces must be considered, these crystal structures provide unequivocal evidence supporting the formation of distinct syn-11a and anti-11b conformations (Fig. 6(a) and (b) respectively). Key parameters for the X-ray crystallographic measurements are provided in S18 and S21. $\dagger$

An interesting structural feature revealed in Fig. 6 is the noticeable deviation of the 2,3,5,6-tetramethylphenyl core from planarity (view 2). The syn-11a conformation is co-crystallised with acetonitrile solvent, while the anti-11b conformation is co-crystallised with approximately $6 \%$ of a mono-epoxide impurity.

The presence of co-crystallised epoxide for anti-11b was unexpected, and re-examination of the high resolution mass spectrometry for samples prior to crystallisation revealed a second signal in the mass spectra of both compounds within $37 \mathrm{ppm}$ of the theoretical mass for molecular formula with an
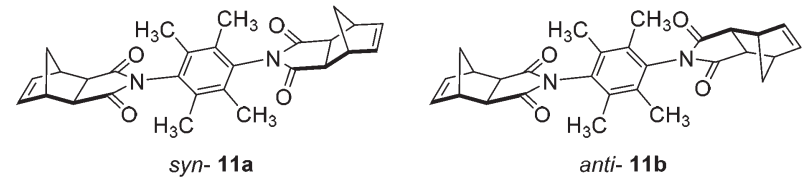

Fig. 5 exo-Analogues syn-11a and anti-11b.

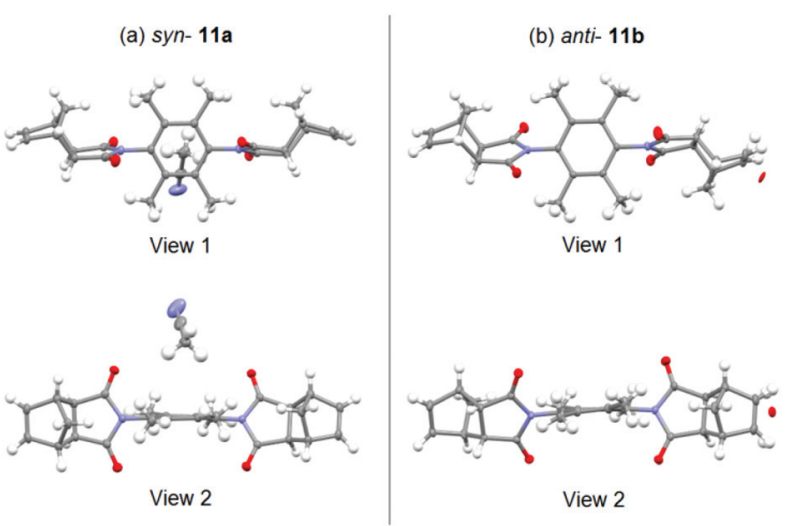

Fig. 6 X-ray crystal structures of the exo-analogues; (a) syn-11a (crystallised with a molecule of acetonitrile), (b) anti-11b (co-crystallised with approximately 6\% mono-epoxide). Images rendered in Mercury (CCDC). ${ }^{91}$ 
additional oxygen atom (i.e. epoxide, $[\mathrm{M}+\mathrm{O}+\mathrm{Na}]^{+}$). There is a literature report of partial epoxide conversion of similar polycyclic derivatives during recrystallisation, ${ }^{92}$ in which epoxidation is also undertaken chemically using an initiator in the presence of molecular oxygen, however it is conceivable that uninitiated epoxidation could occur at a rate too low for convenient measurement. ${ }^{92}$

\section{Host-guest complexations of tweezer 3 with DABCO}

The interaction of the zinc(II) metallated tweezer 3 with the diamino ligand DABCO was studied independently for syn-3a and anti-3b, using UV/Vis and NMR spectroscopic titrations. Complexation models, association constants and speciation diagrams were calculated from the UV/Vis titration data similarly to other published approaches, ${ }^{14,17,28,95-103}$ using HypSpec and HySS2009 (Protonic software). ${ }^{104,105}$

syn-3a. The syn-host 3a can form various complexes with DABCO in solution, all of which are in equilibrium. These possibilities are outlined schematically in Fig. 7, and reveal the possibility of $1: 1(3 \mathrm{a}+\mathrm{DABCO}) \rightleftharpoons 3 \mathrm{a} \cdot \mathrm{DABCO} ; K_{11}=$ $[3 \mathrm{a} \cdot \mathrm{DABCO}] /([3 \mathrm{a}][\mathrm{DABCO}]), \quad 1: 2(3 \mathrm{a}+2 \cdot \mathrm{DABCO}) \rightleftharpoons$ $3 \mathbf{a} \cdot(\mathrm{DABCO})_{2} ; K_{12}=\left[\mathbf{3 a} \cdot(\mathrm{DABCO})_{2}\right] /\left([3 \mathbf{a}][\mathrm{DABCO}]^{2}\right)$, and $2: 1$ $(2 \cdot 3 \mathbf{a}+\mathrm{DABCO}) \rightleftharpoons(3 \mathbf{a})_{2} \cdot \mathrm{DABCO} ; K_{21}=\left[(3 \mathbf{a})_{2} \cdot \mathrm{DABCO}\right]$ $\left([3 \mathrm{a}]^{2}[\mathrm{DABCO}]\right)$ stoichiometries.

UV/Vis titration of a solution of DABCO into a solution of $s y n-3 a$ resulted in a two-stage red shift of the Soret maximum (Fig. 8), indicating the stepwise formation of two dominant complexes between syn-3a and DABCO. The first red shift, from $418.3 \mathrm{~nm}$ (red line) to $423.4 \mathrm{~nm}$ (blue line) is characteristic of a bis-porphyrin DABCO sandwich complex formation. ${ }^{106,107}$ A second gradual red shift occurs to $428.6 \mathrm{~nm}$ (green line) by 400000 equivalents of DABCO, although this transition appears to only be partially complete. This is characteristic of simple mono-porphyrin DABCO complexes. ${ }^{106,107}$

Fitting of the UV/Vis titration data using HypSpec ${ }^{104,105}$ resulted in reasonable fits (visual inspection) to two different complexation models, including either the formation of $3 \mathbf{a} \cdot \mathrm{DABCO}$ and $\mathbf{3 a} \cdot(\mathrm{DABCO})_{2}$ or the formation of $(3 \mathbf{a})_{2} \cdot(\mathrm{DABCO})_{2}$ and $3 \mathbf{a} \cdot(\mathrm{DABCO})_{2}$ (Fig. 7).

Fitting of an algorithm (Fig. 9 using the HypSpec proto$\mathrm{col}^{104,105}$ ) for the formation of the $1: 1$ complex $3 \mathrm{a} \cdot \mathrm{DABCO}$ and

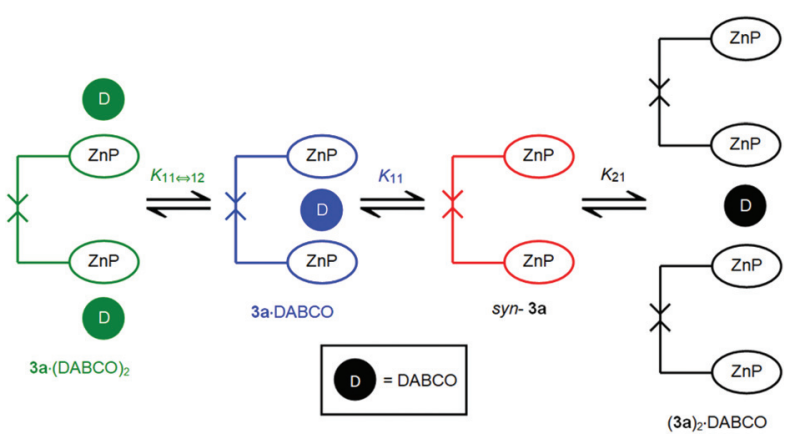

Fig. 7 Schematic representation of the various equilibria between syn$3 a$ and DABCO.

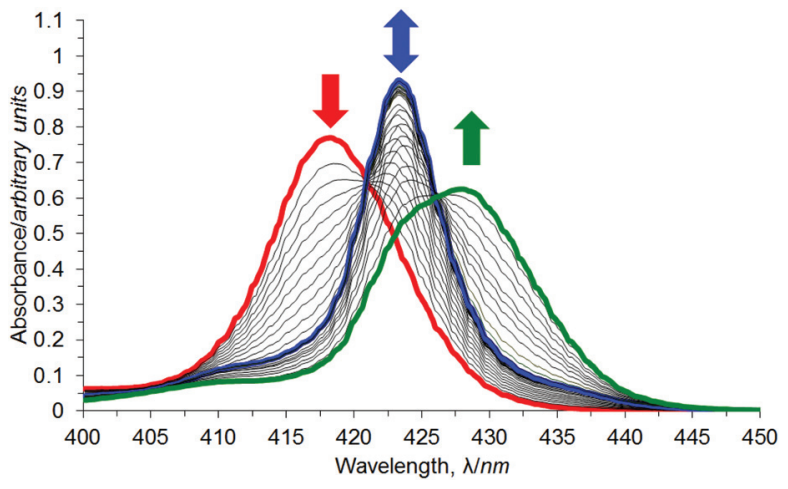

Fig. 8 UV/Vis titration of syn-3a (red line) with DABCO in chloroform.
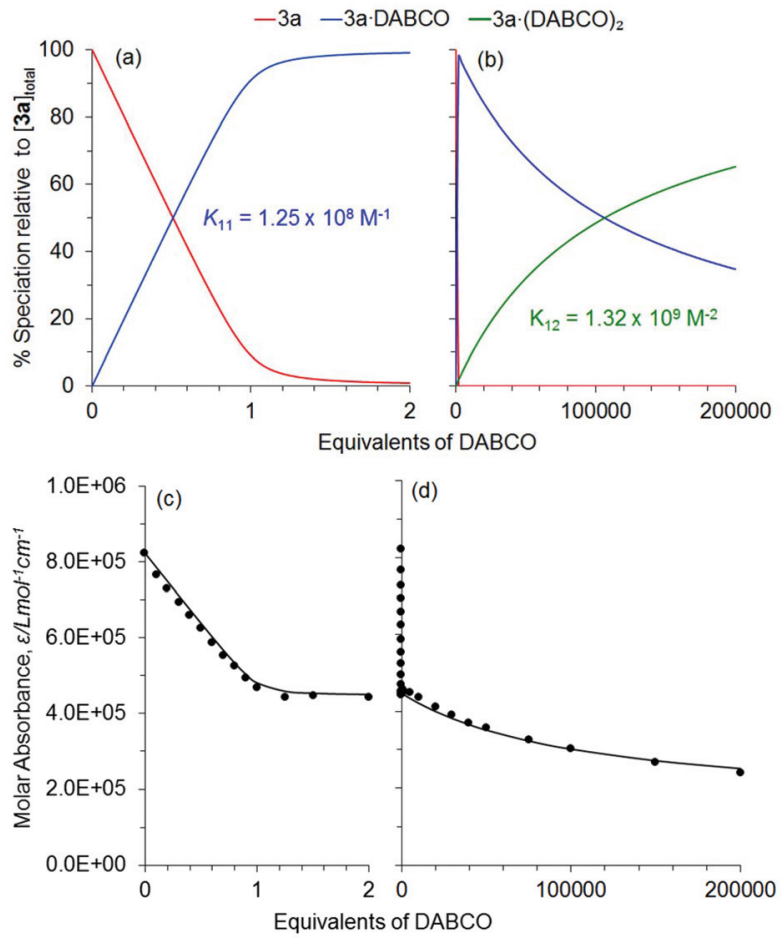

Fig. 9 Derived speciation plots (a) and (b) for formation of 3a.DABCO (blue line) and $3 a \cdot(\mathrm{DABCO})_{2}$ (green line) in the 0-2 equivalent and 0-200 000 equivalent ranges of added DABCO, respectively, in $\mathrm{CHCl}_{3}$ at $20{ }^{\circ} \mathrm{C}$. The corresponding best fits, (c) and (d), of an algorithm for the formation of the 1:1 complex 3a.DABCO and the 1:2 complex $3 a \cdot(D A B C O)_{2}$ (black lines) for the UV/Vis absorbance data obtained at $419 \mathrm{~nm}$ (black circles).

the $1: 2$ complex $3 \mathbf{a} \cdot(\mathrm{DABCO})_{2}$ (Fig. 7) to absorbance data at $419 \mathrm{~nm}$ obtained over a range of 200000 equivalents of added DABCO yielded $K_{11}=1.25 \times 10^{8} \mathrm{M}^{-1}$ and $K_{12}=1.32 \times 10^{9} \mathrm{M}^{-2}$ in $\mathrm{CHCl}_{3}$ at $20^{\circ} \mathrm{C}$. This corresponds to a stepwise $K_{12}^{\prime}=10.6 \mathrm{M}^{-1}$ for the complexation of DABCO by $3 \mathbf{a} \cdot \mathrm{DABCO}$ to give $3 a \cdot(D A B C O)_{2}$. The derived speciations for the complexation in the $0-2$ and $0-200000$ equivalents of added DABCO ranges are show in Fig. 9(a) and (b), and the corresponding data fits at $419 \mathrm{~nm}$ are shown in Fig. 9(c) and (d), respectively. Similar 
data fits were obtained at 423 and $430 \mathrm{~nm}$ (not shown). The $K_{11}=1.25 \times 10^{8} \mathrm{M}^{-1}$ characterising $3 \mathrm{a} \cdot \mathrm{DABCO}$ is much larger than $K_{11}=2.53 \times 10^{5} \mathrm{M}^{-1}$ (not statistically corrected) for monoporphyrin-quinuclidine, ${ }^{15}$ and is consistent with $3 \mathrm{a} \cdot \mathrm{DABCO}$ involving bis-porphyrin complexation in the sandwich structure shown in Fig. $7^{13,17,18}$

The UV/Vis titration data for syn-3a/DABCO could also be fitted to a complexation model involving the formation of $(3 \mathrm{a})_{2}:(\mathrm{DABCO})_{2}\left(K_{22}=1.29 \times 10^{22} \mathrm{M}^{-3}\right)$ and $3 \mathrm{a}:(\mathrm{DABCO})_{2}\left(K_{12}=\right.$ $\left.1.90 \times 10^{9} \mathrm{M}^{-2}\right)(\mathrm{S} 23 \dagger)$. However, the geometric constraints imposed by restricted phenyl core rotation in syn-3a limits the opportunity to form bis-porphyrin interactions with DABCO in $(3 \mathrm{a})_{2}(\mathrm{DABCO})_{2}$.

The $K_{11}=1.25 \times 10^{8} \mathrm{M}^{-1}$ characterising syn-3a.DABCO is approximately double that determined for freely rotating 1.DABCO $\left(K_{11}=8.1 \times 10^{7} \mathrm{M}^{-1}\right) \cdot{ }^{15}$ This fits with the arc through which the two porphyrin moieties are able to move; $360^{\circ}$ in 1 and $180^{\circ}$ for syn-3a. This equates to syn-3a being approximately twice as pre-organised as freely rotating $\mathbf{1}$, and which is reflected in a nearly doubling of $K_{11}$.

An assessment of the validity of the complexation model derived from the UV/Vis titration (carried out at micromolar concentration) may be made by using the derived complexation constants to predict the behaviour of the system during a ${ }^{1} \mathrm{H}$ NMR titration (carried out at millimolar concentration). ${ }^{59,106-108}$ Thus, ${ }^{1} \mathrm{H}$ NMR titrations of $\operatorname{syn}$-3a/DABCO were undertaken in $\mathrm{CDCl}_{3}$.

The resonances of sandwich syn-3a porphyrin $\beta$-pyrrole and sandwich DABCO are diagnostic in the interpretation of the complexation occurring during ${ }^{1} \mathrm{H}$ NMR titrations. At $20{ }^{\circ} \mathrm{C}$, the $\beta$-pyrrole signals for free syn-3a occur at $8.92-8.75 \mathrm{ppm}$ (Fig. 10(a)). The addition of up to 0.9 equivalents of DABCO (integration suggests 1 equivalent) $\dagger \dagger$ results in the appearance of a second syn-3a $\beta$-pyrrole signal at $8.55 \mathrm{ppm}$. This upfield shift is typical of $\beta$-pyrrole protons in a bis-porphyrin DABCO sandwich complex as a consequence of shielding by opposing ring currents of two porphyrin aromatic systems in close proximity. ${ }^{96,106,107}$ The two syn-3a species are in slow exchange on the NMR chemical shift timescale, and the syn-3a complex resonance intensity increases as that of free syn-3a decreases. The relative integration of the syn-3a complex $\beta$-pyrrole resonance to that of the total syn-3a $\beta$-pyrrole resonance (free plus complex) is consistent with the formation of a $1: 1$ complex (within $10 \%$ error), such as $3 \mathbf{a} \cdot \mathrm{DABCO}$ or $(\mathbf{3 a})_{2} \cdot(\mathrm{DABCO})_{2}$, and is later shown to be the former. Addition of greater than 1 equivalent of DABCO causes the syn-3a $\beta$-pyrrole resonance to shift downfield as increasing proportions of the $3 \mathrm{a} \cdot(\mathrm{DABCO})_{2}$ complex forms in fast exchange with $3 \mathrm{a} \cdot \mathrm{DABCO}$ on the NMR chemical shift timescale. However, the change in chemical shift of this syn-3a resonance after the addition of 5 equivalents of DABCO $(\Delta \delta=0.033 \mathrm{ppm})$ is small compared to that of the freely rotating tweezer $1(\Delta \delta=0.082 \mathrm{ppm}$ (ref. 90)) under

$\dagger \dagger$ The error between the number of equivalents of DABCO titrated with tweezer 3 , based on mass weighed, compared to the NMR signal integration was estimated to be $10 \%$ at $20{ }^{\circ} \mathrm{C}$ for both syn-3a and anti-3b, $20 \%$ at $-50{ }^{\circ} \mathrm{C}$ for $s y n-3 \mathbf{a}$, and $10-15 \%$ at -50 to $-60{ }^{\circ} \mathrm{C}$ for anti-3b.
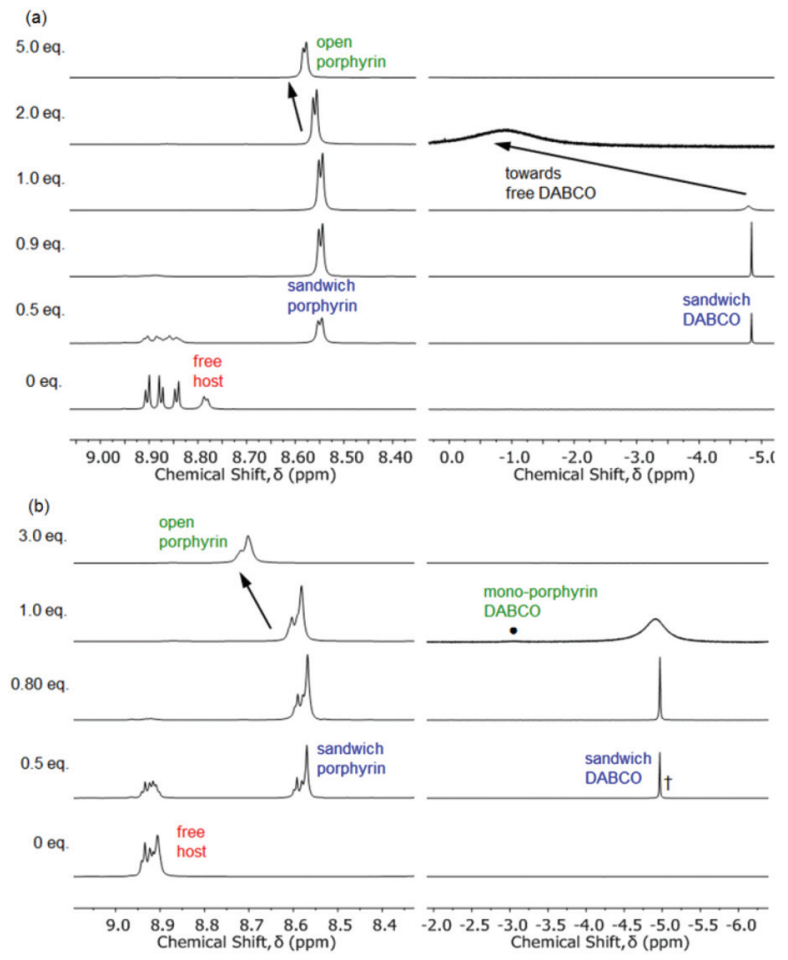

Fig. 10 Selected ${ }^{1} \mathrm{H}$ NMR spectra of syn-3a with various equivalents of $\mathrm{DABCO}$ at (a) $20^{\circ} \mathrm{C}$ and (b) $-50{ }^{\circ} \mathrm{C}$. $\dagger$ identifies minor amounts of an additional sandwich complex. identifies the mono-porphyrin.DABCO signal broadened into the baseline due to chemical exchange. Spectra recorded at $600 \mathrm{MHz}$ in $\mathrm{CDCl}_{3}$.

the same conditions, consistent with the $3 \mathbf{a} \cdot \mathrm{DABCO}$ complex being less amenable to the addition of a second DABCO than is the $\mathbf{1} \cdot \mathrm{DABCO}$ complex.

The syn-3a porphyrin meso-phenyl proton resonances (not shown) are broadened in the presence of less than 1 equivalent of DABCO but sharpen in the presence of greater than 1 equivalent of DABCO and shift downfield, presumably as the sandwich complex forms and undergoes fast exchange with the open syn-3a complex with DABCO, 3a·(DABCO $)_{2}$. Little information could be obtained from the polycyclic resonances.

Further understanding of the complexation of DABCO by $s y n-3 \mathbf{a}$ is gained from the DABCO methylene resonance (Fig. 10(a)). For the addition of up to 0.9 equivalents of DABCO (integration suggests 1 equivalent), a sharp singlet was observed at $-4.84 \mathrm{ppm}$. This large upfield shift is typical of DABCO methylene protons in a bis-porphyrin DABCO sandwich complex, and again results from shielding by opposing ring currents of two porphyrin aromatic systems in close proximity. ${ }^{96,106,107,109-112}$ The relative integration of the DABCO sandwich resonance to the syn-3a ester signaltt is con-

$\$$ The ester signal was selected as a reference because it does not change chemical shift significantly on complexation, and its integration is the sum of free plus complexed species. Conveniently, the number of protons in the host ester resonance is equal to the number of protons in an isolated molecule of free $\mathrm{DABCO}$, and so their relative integrations do not require any normalisation. 
sistent with the formation of a species with the empirical formula of $1: 1$ (within 10\% error). At 1 equivalent and greater of DABCO, the sandwich DABCO resonance broadens, and migrates downfield towards the value for free DABCO. This is consistent with chemical exchange with another species occurring at a fast exchange rate on the NMR chemical shift timescale at $20{ }^{\circ} \mathrm{C}$, most likely a combination of $3 \mathbf{a} \cdot(\mathrm{DABCO})_{2}$ and free DABCO.

At less than 1 equivalent of DABCO, all resonances, including the syn-3a porphyrin and polycyclic resonances, are in slow exchange on the NMR chemical shift timescale, however, several of the free syn-3a host resonances undergo simultaneous resonance shifts as their signal intensity is depleted and the complex resonance increases (not shown). This was particularly obvious for the methylene bridgehead proton at 1.0-1.3 ppm and the porphyrin $\beta$-pyrrole resonance. This phenomenon appears to indicate a second process occurring in addition to formation of the sandwich complex. This could be attributed to the concentration dependence of the free host ${ }^{1} \mathrm{H}$ NMR spectrum discussed earlier (S12(a) $\dagger$ ). In this case, as the syn-3a complex forms, the free syn-3a concentration decreases and its concentration dependent chemical shift changes.

Slowing the exchange rate between the various syn-3a complexes in solution was achieved by lowering the sample temperature to $-50{ }^{\circ} \mathrm{C}$ (Fig. 10(b)), and revealed several additional spectral features. Below 0.8 equivalents of DABCO (integration suggests 1 equivalent), a small amount of an additional sandwich syn-3a complex in addition to the main signal can be observed around $-5 \mathrm{ppm}$ (indicated by $\dagger$ in Fig. 10(b)). At greater than 0.8 equivalents of DABCO (spectral features suggest greater than 1 equivalent), the system moves into fast exchange on the NMR chemical shift timescale. A small amount of the open syn-3a complex can be observed at $-3.06 \mathrm{ppm}$ (indicated by in Fig. 10(b)) in addition to the main sandwich syn-3a complex resonance, now broadened due to chemical exchange. The resonance at $-3.06 \mathrm{ppm}$ is characteristic of the $\alpha$ methylene protons of DABCO bound to a single porphyrin, ${ }^{106,108,111}$ and most likely corresponds to conversion of the sandwich syn-3a complex to open species, in this case $3 \mathrm{a} \cdot(\mathrm{DABCO})_{2}$.

The porphyrin meso-phenyl protons (not shown) are sharp and highly desymmetrised below 1 equivalent of DABCO, indicating facial differentiation of the porphyrins within the sandwich complex. For greater than 1 equivalent of DABCO, the porphyrin meso-phenyl protons broaden and resymmetrise, suggesting diminishing facial discrimination, then shift downfield, presumably as the sandwich complex undergoes fast exchange with open species on the NMR chemical shift timescale. Little information could be obtained from the polycyclic resonances.

To further investigate the composition of the complex formed between syn-3a and DABCO at NMR concentrations (millimolar), a simulated NMR speciation diagram was generated in HySS2009 $9^{104,105}$ using the association constants for successfully fitted complexation models determined from the

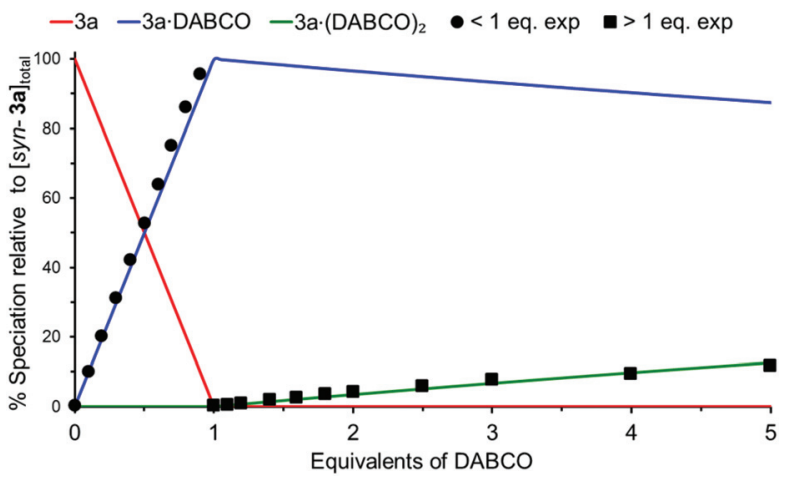

Fig. 11 Simulated NMR speciation diagram (millimolar) generated from UV/Vis determined association constants $K_{11}$ and $K_{12}$ for syn-3a/DABCO (micromolar). Experimental NMR speciation has been overlayed for both the slow and fast exchange regions of the titration.

UV/Vis titrations (micromolar), and compared with experimental NMR titration data. ${ }^{106-108}$ Fig. 11 shows this result for the $1: 1$ plus $1: 2$ complexation model, where the blue line represents the predicted NMR speciation for the growth and decay of $3 \mathrm{a} \cdot \mathrm{DABCO}$, the green line represents the open species $3 \mathrm{a} \cdot(\mathrm{DABCO})_{2}$, and the red line represents free host. The black circles and squares represent the experimental speciation for the slow and fast exchange NMR chemical shift timescale regions respectively, calculated as described in $\mathrm{S} 22 . \dagger \S \S$

As can be seen in Fig. 11, there is excellent agreement between the simulated and experimental speciation across both the slow and fast exchange NMR chemical shift timescale regions. This confirmed that the complexation model was the same at both UV/Vis and NMR concentrations for the syn-3a/ DABCO system; formation of the sandwich complex 3a.DABCO and gradual decay of the sandwich complex into open complex 3a.(DABCO $)_{2}$. The simulated NMR speciation for the alternative complexation model from the UV/Vis data involving the formation of $(3 \mathbf{a})_{2} \cdot(\mathrm{DABCO})_{2}$ and $3 \mathbf{a} \cdot(\mathrm{DABCO})_{2}$ is shown in $\mathrm{S} 23, \uparrow$ however, does not match the experimental data for the formation of the open species $3 \mathbf{a} \cdot(\mathrm{DABCO})_{2}$.

anti-3b. On the other hand, the geometric constraints imposed by the restricted rotation of the phenyl core enable the anti-conformation to form different complexes to the synconformation. The anti-3b host can form various complexes with DABCO in solution, all of which are in equilibrium. These possibilities are outlined schematically in Fig. 12, and reveal the possibility of $2: 2(2 \cdot 3 \mathbf{b}+2 \cdot \mathrm{DABCO}) \rightleftharpoons$ $(3 \mathbf{b})_{2} \cdot(\mathrm{DABCO})_{2} ; K_{22}=\left[(\mathbf{3 b})_{2} \cdot(\mathrm{DABCO})_{2}\right] /\left([3 \mathbf{b}]^{2}[\mathrm{DABCO}]^{2}\right), 1: 2$ $(3 \mathbf{b}+2 \cdot \mathrm{DABCO}) \rightleftharpoons \mathbf{3 b} \cdot(\mathrm{DABCO})_{2} ; \quad K_{12}=\left[3 \mathbf{b} \cdot(\mathrm{DABCO})_{2}\right] /$ $\left([3 \mathbf{b}][\mathrm{DABCO}]^{2}\right), 2: 1(2 \cdot 3 \mathbf{b}+\mathrm{DABCO}) \rightleftharpoons(3 \mathbf{b})_{2} \cdot \mathrm{DABCO} ; K_{21}=$ $\left[(\mathbf{3 b})_{2} \cdot \mathrm{DABCO}\right] /\left([\mathbf{3 b}]^{2}[\mathrm{DABCO}]\right)$ stoichiometries, as well as a $n: n$ polymeric assembly $(n \cdot \mathbf{3} \mathbf{b}+n \cdot \mathrm{DABCO}) \rightleftharpoons(\mathbf{3 b})_{n} \cdot(\mathrm{DABCO})_{n} ; K_{n n}=$ $\left[(3 \mathbf{b})_{n} \cdot(\mathrm{DABCO})_{n}\right] /\left([3 \mathbf{b}]^{n}[\mathrm{DABCO}]^{n}\right)$.

$\S \S$ A chemical shift of $8.548 \mathrm{ppm}($ syn-3a +0.9 eq. DABCO) was selected for the value for fully complexed species. A chemical shift of $8.829 \mathrm{ppm}($ anti-3b +5 eq. DABCO) was selected for the value for fully open species. 


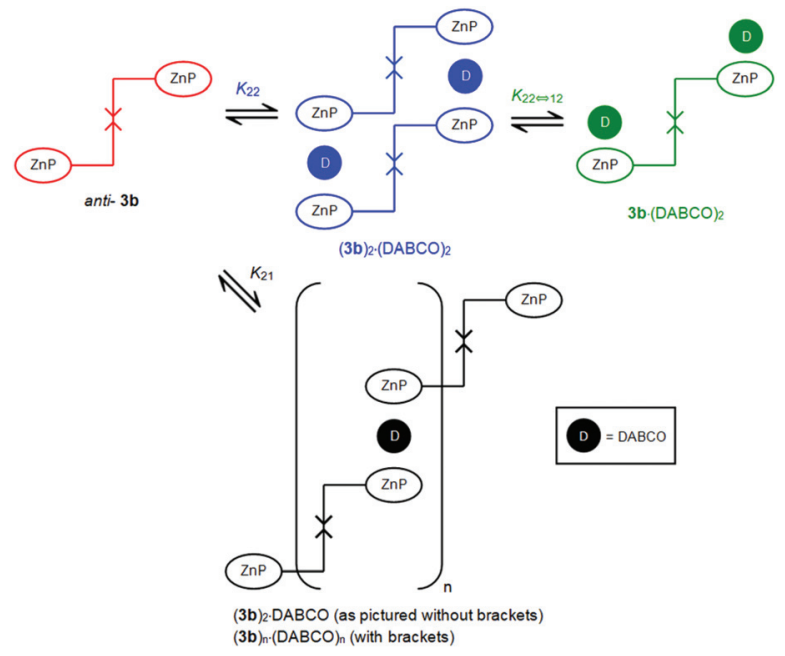

Fig. 12 Schematic representation of the various equilibria between anti-3b and DABCO.

$\mathrm{UV} /$ Vis titration of a solution of DABCO into a solution of anti-3b again resulted in a two-stage redshift of the Soret maximum (Fig. 13), indicating the stepwise formation of two dominant complexes between anti-3b and DABCO. The first red shift, from $419.5 \mathrm{~nm}$ (red line) to $423.5 \mathrm{~nm}$ (blue line) is characteristic of a bis-porphyrin DABCO sandwich complex formation. ${ }^{106,107}$ However, this sandwich species is transient, and a second redshift occurs to $430.0 \mathrm{~nm}$ (green line) by 10000 equivalents of DABCO, after which this transition appears to be complete. This is characteristic of simple monoporphyrin DABCO complexes. ${ }^{106,107}$

Fitting of the UV/Vis titration data using HypSpec ${ }^{104,105}$ resulted in reasonable fits (visual inspection) to several different complexation models, including the formation of $(3 \mathbf{b})_{2} \cdot(\mathrm{DABCO})_{2}$ and $\mathbf{3 b} \cdot(\mathrm{DABCO})_{2}$, and the formation of 3b·DABCO and $\mathbf{3 b} \cdot(\mathrm{DABCO})_{2}$ (Fig. 12).

Fitting of an algorithm (Fig. 14 using the HypSpec proto$\mathrm{col}^{104,105}$ ) for the formation of the $2: 2$ complex $(3 \mathbf{b})_{2} \cdot(\mathrm{DABCO})_{2}$ and the $1: 2$ complex $3 \mathbf{b} \cdot(\mathrm{DABCO})_{2}$ (Fig. 12) to absorbance data at $419 \mathrm{~nm}$ obtained over a range of 10000

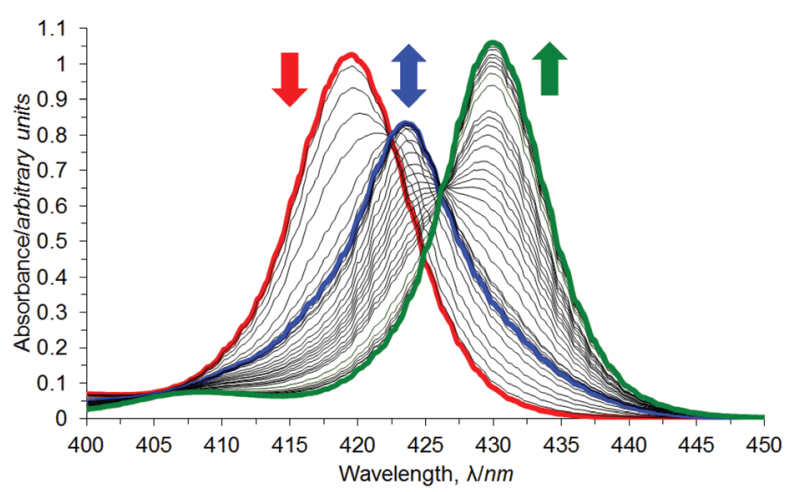

Fig. $13 U V /$ Vis titration of anti-3b (red line) with DABCO in chloroform.
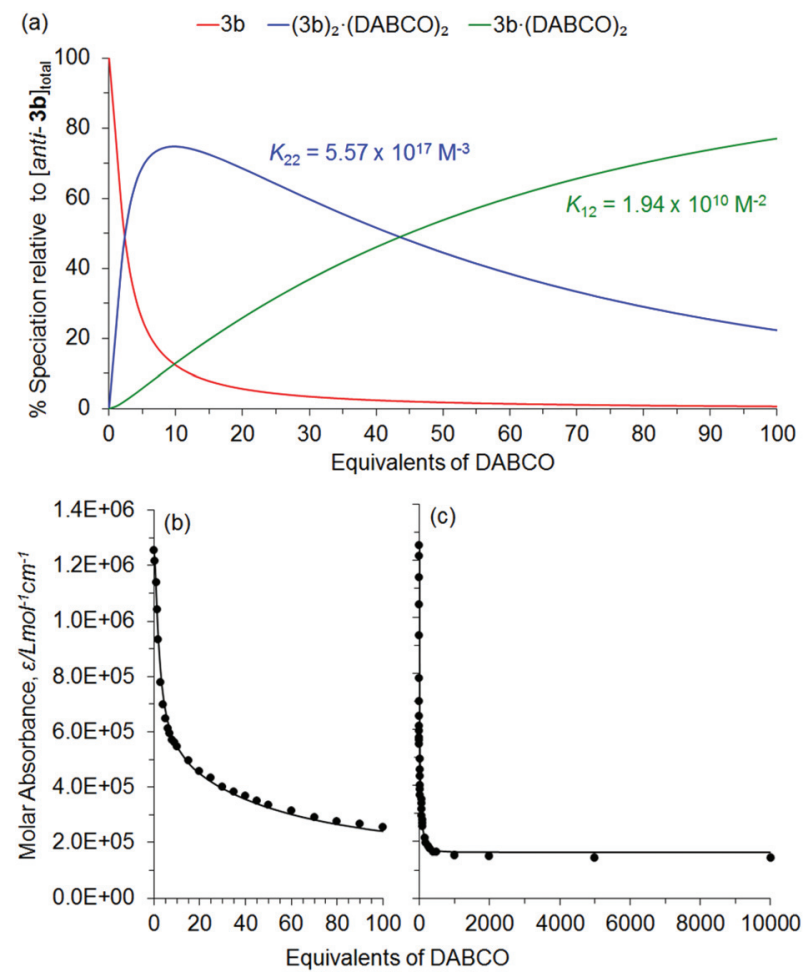

Fig. 14 Derived speciation plot (a) for formation of $(3 b)_{2} \cdot(D A B C O)_{2}$ (blue line) and $3 b \cdot(D A B C O)_{2}$ (green line) for 0-10000 equivalents of added $\mathrm{DABCO}$ in $\mathrm{CHCl}_{3}$ at $20^{\circ} \mathrm{C}$. The corresponding best fits, (c) and (d), of an algorithm for the formation of the $2: 2$ complex $(3 b)_{2} \cdot(D A B C O)_{2}$ and the $1: 2$ complex $3 b \cdot(D A B C O)_{2}$ (black lines) for the UV/Vis absorbance data obtained at $419 \mathrm{~nm}$ (black circles) for 0-100 and 0-10 000 equivalents of added DABCO respectively.

equivalents of added DABCO yielded $K_{22}=5.57 \times 10^{17} \mathrm{M}^{-3}$ and $K_{12}=1.94 \times 10^{10} \mathrm{M}^{-2}$ in $\mathrm{CHCl}_{3}$ at $20{ }^{\circ} \mathrm{C}$. The value for $K_{22}$ compares well to other similar porphyrin-DABCO sandwich complexes in the literature $\left(K_{22}=6.2 \times 10^{16}-6.3 \times 10^{22} \mathrm{M}^{-3}\right){ }^{106-108}$ The derived speciation for the complexation with 0-10000 equivalents of added DABCO is shown in Fig. 14(a), and the corresponding data fit at $419 \mathrm{~nm}$ is shown in Fig. 14(b) and (c), for 0-100 and 0-10 000 equivalents of added DABCO respectively. Similar data fits were obtained at 423 and $430 \mathrm{~nm}$ (not shown).

The UV/Vis titration data for anti-3b/DABCO could also be fitted to a complexation model involving the formation of $3 \mathbf{b} \cdot \operatorname{DABCO}\left(K_{11}=7.16 \times 10^{5} \mathrm{M}^{-1}\right)$ and $\mathbf{3 b} \cdot(\mathrm{DABCO})_{2}\left(K_{12}=2.17 \times\right.$ $\left.10^{10} \mathrm{M}^{-2}\right)(\mathrm{S} 24 \dagger)$. However, the goodness of the fit alone cannot be used as the criterion to decide the correct complexation model, ${ }^{106}$ and all aspects of the fitting output should be examined $(\mathrm{S} 22 \dagger)$. In this case, the calculated UV/Vis spectra in the HypSpec output (not shown) suggested the $\mathbf{3 b} \cdot \mathrm{DABCO}$ species had a wavelength maxima centred around $423 \mathrm{~nm}$, which would experimentally suggest a bis-porphyrin DABCO sandwich complex. However, the geometric constraints imposed by restricted phenyl core rotation in anti-3b limit the opportunity to form bis-porphyrin interactions with DABCO in $\mathbf{3 b} \cdot \mathrm{DABCO}$, and so this complexation model was excluded. 
Subsequently, ${ }^{1} \mathrm{H}$ NMR titrations of anti-3b/DABCO were undertaken in $\mathrm{CDCl}_{3}$. At $20{ }^{\circ} \mathrm{C}$, the $\beta$-pyrrole signals for free anti-3b occur at 8.96-8.94 ppm (Fig. 15(a)). The addition of up 0.9 equivalents of DABCO (integration suggests 1 equivalent) $\dagger \dagger$ results in the appearance of a second anti-3b $\beta$-pyrrole signal for the complex at $8.55 \mathrm{ppm}$. The two anti-3b species are in slow to medium exchange on the NMR chemical shift timescale (resonances are broad but distinct) and the anti-3b complex resonance intensity increases as that of free anti-3b decreases. The relative integration of the anti-3b complex $\beta$-pyrrole resonance to that of the total anti-3b $\beta$-pyrrole resonance (free plus complex) is consistent with the formation of a species with the empirical formula of $1: 1$ (within 10\% error), such as $(\mathbf{3 b})_{2} \cdot(\mathrm{DABCO})_{2}$ or $(\mathbf{3 b})_{n} \cdot(\mathrm{DABCO})_{n}$. This chemical shift of this complex resonance $(8.55 \mathrm{ppm})$ is typical of $\beta$-pyrrole protons in a bis-porphyrin DABCO sandwich, ${ }^{96,106,107}$ and so a complexation model involving $3 \mathbf{b} \cdot \mathrm{DABCO}$ can again be excluded due to geometric constraints as previously discussed. Addition of greater than 1 equivalent of DABCO causes the anti-3b $\beta$-pyrrole resonance to shift downfield as increasing proportions of $\mathbf{3 b} \cdot(\mathrm{DABCO})_{2}$ forms in fast exchange with $(3 \mathbf{b})_{2} \cdot(\mathrm{DABCO})_{2}$ on the NMR chemical shift timescale. However, the change in chemical shift of this anti-3b resonance after the addition of 5 equivalents of DABCO $(\Delta \delta=$
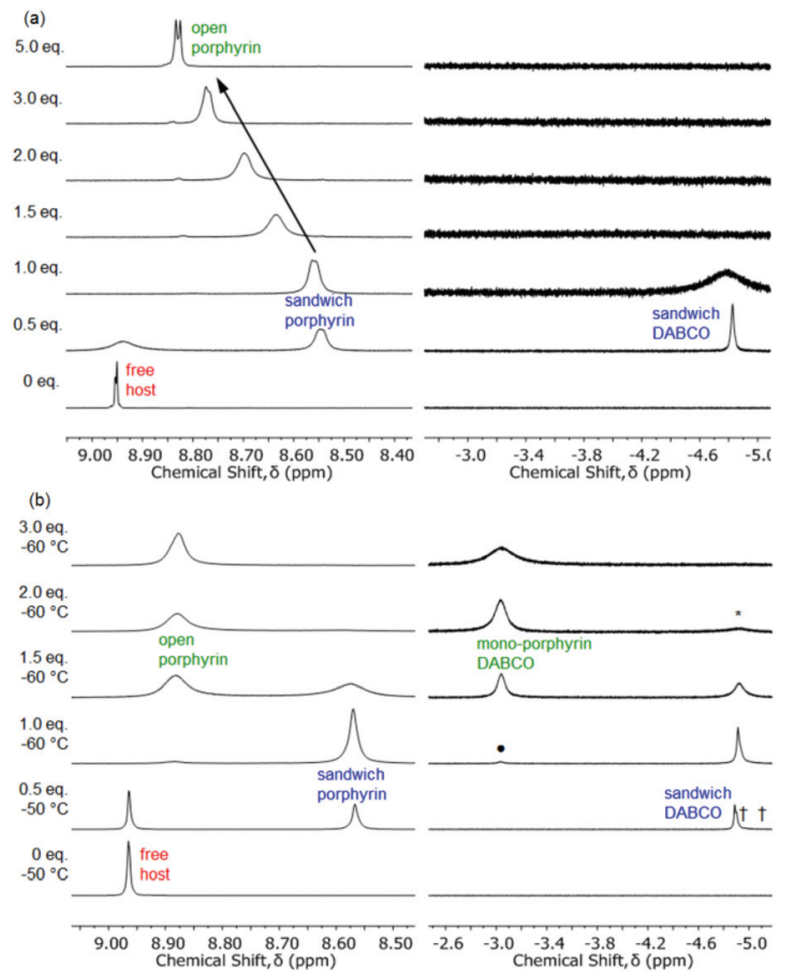

Fig. 15 Selected ${ }^{1} \mathrm{H}$ NMR spectra of anti-3b with various equivalents of $\mathrm{DABCO}$ at (a) $20^{\circ} \mathrm{C}$ and (b) -50 to $-60^{\circ} \mathrm{C}$. $\dagger$ identifies additional sandwich complexes. * identifies $\mathrm{DABCO}$ sandwich signals broadened into the baseline due to chemical exchange. - identifies the monoporphyrin.DABCO signal broadened into the baseline due to chemical exchange. Spectra recorded at $600 \mathrm{MHz}$ in $\mathrm{CDCl}_{3}$.
$0.282 \mathrm{ppm}$ ) is larger than for the freely rotating $\mathbf{1}$ and syn-3a tweezer systems $(\Delta \delta=0.082$ (ref. 90) and 0.033 ppm respectively) under the same conditions. This demonstrates the increased formation of $\mathbf{3} \mathbf{b} \cdot(\mathrm{DABCO})_{2}$ from $(\mathbf{3} \mathbf{b})_{2} \cdot(\mathrm{DABCO})_{2}$ for excess DABCO, compared to $\mathbf{1} \cdot(\mathrm{DABCO})_{2}$ from $\mathbf{1} \cdot \mathrm{DABCO}$, and $3 \mathbf{a} \cdot(\mathrm{DABCO})_{2}$ from $3 \mathbf{a} \cdot \mathrm{DABCO}$.

The anti-3b porphyrin $\beta$-pyrrole (shown) and meso-phenyl signals (not shown) are broadened in the presence of less than 5 equivalents of DABCO, at which point they sharpen after the shift downfield, presumably as $(3 \mathbf{b})_{2} \cdot(\mathrm{DABCO})_{2}$ undergoes fast exchange with increasing proportions of $\mathbf{3 b} \cdot(\mathrm{DABCO})_{2}$. Little information could be obtained from the polycyclic resonances.

Further understanding of the complexation of DABCO by anti-3b is gained from the DABCO methylene resonance (Fig. 15(a)). At 0.1 equivalents of DABCO (not shown), two signals can be observed; major at $-4.826 \mathrm{ppm}$ and minor at $-4.846 \mathrm{ppm}$. This large upfield shift is typical of DABCO methylene protons in a bis-porphyrin DABCO sandwich complex, ${ }^{96,106,107,109-112}$ and indicates the formation of two different sandwich complexes. At 0.5 equivalents of DABCO, only the major signal can be observed, and is a sharp singlet for up to 0.9 equivalents of DABCO (integration suggests 1 equivalent). The relative integration of the DABCO sandwich resonance to the anti-3b ester signaltt is consistent with the formation of a species with the empirical formula of $1: 1$ (within $10-15 \%$ error), such as $(3 \mathbf{b})_{2} \cdot(\mathrm{DABCO})_{2}$ or $(3 \mathbf{b})_{n} \cdot(\mathrm{DABCO})_{n}$. At 1 equivalent and greater of DABCO, the sandwich DABCO resonance broadens. This is consistent with chemical exchange with another species occurring at a fast exchange rate on the NMR chemical shift timescale at $20{ }^{\circ} \mathrm{C}$, most likely a combination of $\mathbf{3 b} \cdot(\mathrm{DABCO})_{2}$ and free DABCO. At 5 equivalents of DABCO, a broad signal was observed between 0.8-2.2 ppm under the polycyclic signals (not shown), shifting towards the resonance for free DABCO.

Slowing the exchange rate between the various anti-3b complexes in solution was achieved by lowering the sample temperature to -50 and $-60{ }^{\circ} \mathrm{C}$ (Fig. 15(b)), and revealed several additional spectral features. Below 0.9 equivalents of DABCO (integration suggests 1 equivalent), two sandwich anti-3b complexes can be identified from the DABCO signals at $-4.89 \mathrm{ppm}$ and $-4.90 \mathrm{ppm}$. The species at $-4.90 \mathrm{ppm}$ is dominant below 0.3 equivalents of DABCO after which the species at -4.89 ppm becomes dominant. A trace quantity of a third sandwich complex was observed at $-4.98 \mathrm{ppm}$. These sandwich species are marked $\dagger$ in Fig. 15(b). Additional evidence for two sandwich anti-3b complexes at low temperature was observed in several of the polycyclic resonances (not shown), several of which are split into three; free anti-3b and two complexes. These are most likely to be different molecular orientations of $(3 \mathbf{b})_{2} \cdot(\mathrm{DABCO})_{2}$ (see molecular modelling section), or $(\mathbf{3 b})_{n} \cdot(\mathrm{DABCO})_{n}$. At greater than 1 equivalent of DABCO, the system remained in slow to intermediate exchange on the NMR chemical shift timescale, and allowed the resonances for the open anti-3b/DABCO complex, $3 \mathbf{b} \cdot(\mathrm{DABCO})_{2}$, to be assigned. The open porphyrin $\beta$-pyrrole resonance for $3 \mathbf{b} \cdot(\mathrm{DABCO})_{2}$ occurs at $8.88 \mathrm{ppm}$, while the DABCO 
$\alpha$-methylene resonance in $3 \mathbf{b} \cdot(\mathrm{DABCO})_{2}$ occurs at $-3.04 \mathrm{ppm}$ (marked $\bullet$ in Fig. 15(b)). Both of these chemical shifts are consistent with DABCO interacting with a monoporphyrin. ${ }^{106,108,111}$ These resonances increase in intensity at the expense of those for the sandwich anti-3b complex, $(3 \mathbf{b})_{2} \cdot(\mathrm{DABCO})_{2}$, with the conversion to $\mathbf{3 b} \cdot(\mathrm{DABCO})_{2}$ almost complete at 2 equivalents of DABCO. This again demonstrates the increased formation of $\mathbf{3} \mathbf{b} \cdot(\mathrm{DABCO})_{2}$ from $(\mathbf{3} \mathbf{b})_{2} \cdot(\mathrm{DABCO})_{2}$ for excess DABCO, compared to $\mathbf{1} \cdot(\mathrm{DABCO})_{2}$ from 1.DABCO, and $3 \mathrm{a} \cdot(\mathrm{DABCO})_{2}$ from $3 \mathrm{a} \cdot \mathrm{DABCO}$. At 3 equivalents of $\mathrm{DABCO}$, the mono-porphyrin $\mathrm{DABCO}$ resonance for $\mathbf{3 b} \cdot(\mathrm{DABCO})_{2}$ broadens, presumably due to exchange with free DABCO.

Interestingly, there is a broad signal at a chemical shift of $0.82 \mathrm{ppm}$ (not shown) at $-50^{\circ} \mathrm{C}$, which increases in intensity between 1-2 equivalents of DABCO. This was tentatively assigned to the $\beta$-methylene of DABCO interacting with a mono-porphyrin, such as $\mathbf{3 b} \cdot(\mathrm{DABCO})_{2}$, in the absence of a literature value (quinuclidine $\beta$-methylene protons occur at $-0.64 \mathrm{ppm}$ for their complex with mono-porphyrins ${ }^{111}$ ).

To further investigate the composition of the complex formed between anti-3b and DABCO at NMR concentrations (millimolar), a simulated NMR speciation diagram was generated in HySS2009 $9^{104,105}$ using the association constants for successfully fitted complexation models determined from the UV/Vis titrations (micromolar), and compared with experimental NMR titration data. ${ }^{106-108}$ Fig. 16 shows this result for the $2: 2$ plus $1: 2$ complexation model, where the blue line represents the predicted NMR speciation for the growth and decay of $(3 \mathbf{b})_{2} \cdot(\mathrm{DABCO})_{2}$, the green line represents the open species $3 \mathbf{b} \cdot(\mathrm{DABCO})_{2}$, and the red line represents free host. The black circles and squares represent the experimental speciation for the slow and fast exchange NMR chemical shift timescale

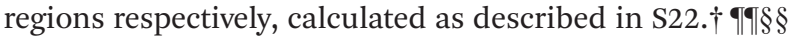

As can be seen in Fig. 16, there is excellent agreement between the simulated and experimental speciation in the slow exchange NMR chemical shift timescale region $(<1$ eq. DABCO), while the simulation follows the same trend as the experimental data in the fast exchange NMR chemical shift timescale region (>1 eq. DABCO). This confirmed that the complexation model was the same at both UV/Vis and NMR concentrations for the anti-3b/DABCO system; formation of the sandwich complex $(3 \mathbf{b})_{2} \cdot(\mathrm{DABCO})_{2}$ and decay of the sandwich complex into open complex $3 \mathbf{b} \cdot(\mathrm{DABCO})_{2}$ (assuming that the major and minor sandwich species observed in the NMR at low equivalents of DABCO are two different molecular orientations of $(3 \mathbf{b})_{2} \cdot(\mathrm{DABCO})_{2}$, and not $\left.(3 \mathbf{b})_{n} \cdot(\mathrm{DABCO})_{n}\right)$. The simulated NMR speciation for the alternative complexation model, $\mathbf{3 b} \cdot \mathrm{DABCO}$ and $\mathbf{3} \mathbf{b} \cdot(\mathrm{DABCO})_{2}$, excluded during the analysis of both the UV/Vis and NMR data, is shown in S24, $\dagger$ however, does not match the experimental data for the formation of either $\mathbf{3} \mathbf{b} \cdot \mathrm{DABCO}$ or $\mathbf{3} \mathbf{b} \cdot(\mathrm{DABCO})_{2}$.

qT The major and minor signals for the sandwich species observed at low equivalents of DABCO were not baseline resolved and so were integrated together, which assumes that the two resonances arise from different molecular orientations of the same complex $(3 \mathbf{b})_{2} \cdot(\mathrm{DABCO})_{2}$.

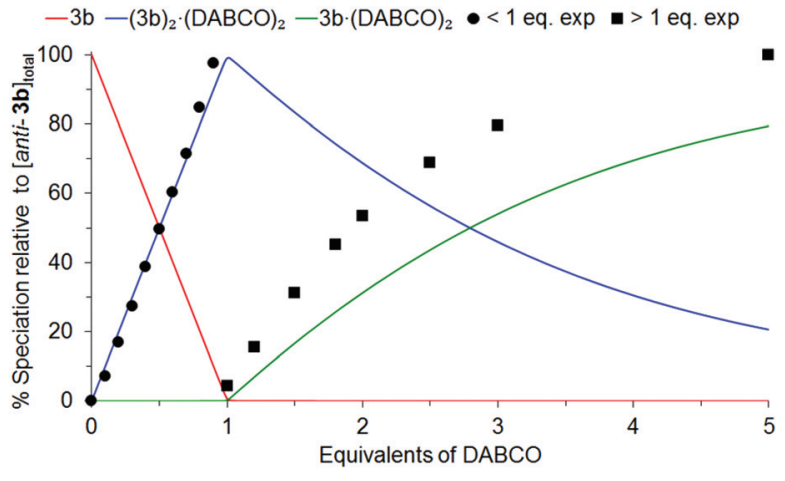

Fig. 16 Simulated NMR speciation diagram (millimolar) generated from UV/Vis determined association constants $K_{22}$ and $K_{12}$ for anti-3b/DABCO (micromolar). Experimental NMR speciation has been overlayed for both the slow and fast exchange regions of the titration.

\section{Molecular modelling}

Molecular modelling ${ }^{93}$ was undertaken to provide information on the equilibrium geometry of the restricted rotation tweezer in the absence of guest (semi-empirical, AM1), and is shown in Fig. 17. For the syn-3a conformation, rotation of the polycyclic arms can be observed about the central 2,3,5,6-tetramethylphenyl diimide group. Although the bis-porphyrins in the free host are not arranged in a cofacial orientation in the model, rotation about porphyrin meso-phenyl groups is well known, ${ }^{113-115}$ and this would enable the formation of the sandwich syn-3a·DABCO complex that is observed experimentally. For the anti-3b conformation, it is evident from the model that a sandwich anti-3b-DABCO complex cannot be accessed due to geometry constraints in the free host, but that the sandwich anti-(3b) $)_{2} \cdot(\mathrm{DABCO})_{2}$ complex that was observed experimentally is supported by the model.

Finally, molecular modelling (semi-empirical, AM1) ${ }^{93}$ was undertaken to determine the equilibrium geometry of DABCO complexes of syn-3a and anti-3b (Fig. 18 and 19). The model of the syn-3a-DABCO complex (Fig. 18) appears similarly to our previously described freely rotating tweezer 1.DABCO. ${ }^{15}$ Rotation is observed about the porphyrin moieties as well as between the two polycyclic arms of the tweezer about the central 2,3,5,6-tetramethylphenyl diimide group. The core is

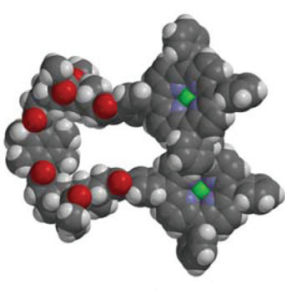

syn- 3a

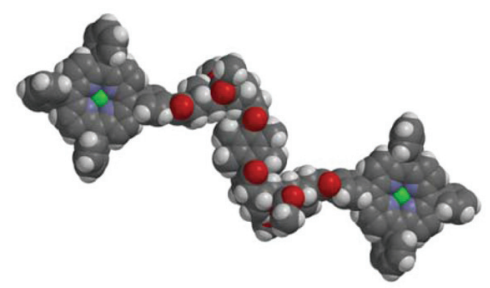

anti- 3b
Fig. 17 Equilibrium geometry of syn-3a and anti-3b in the absence of guest (semi-empirical, AM1). 


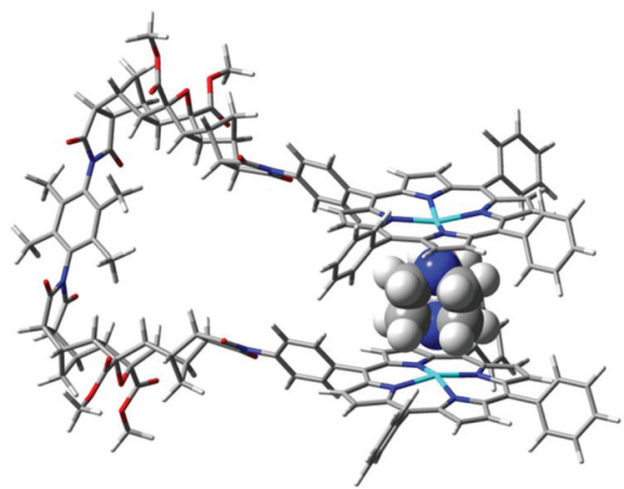

Fig. 18 Equilibrium geometry (semi-empirical, AM1) of syn-3a.DABCO. Image rendered in GaussView. ${ }^{116}$

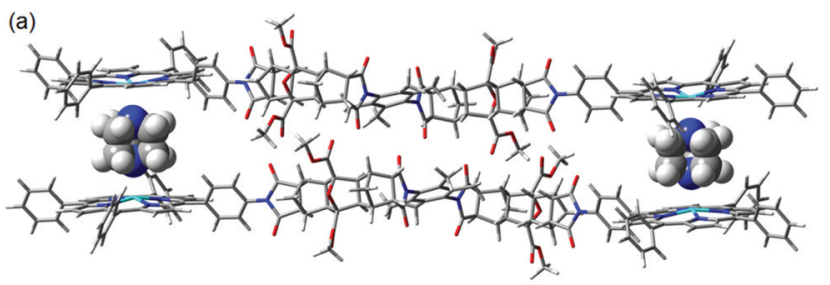

(b)
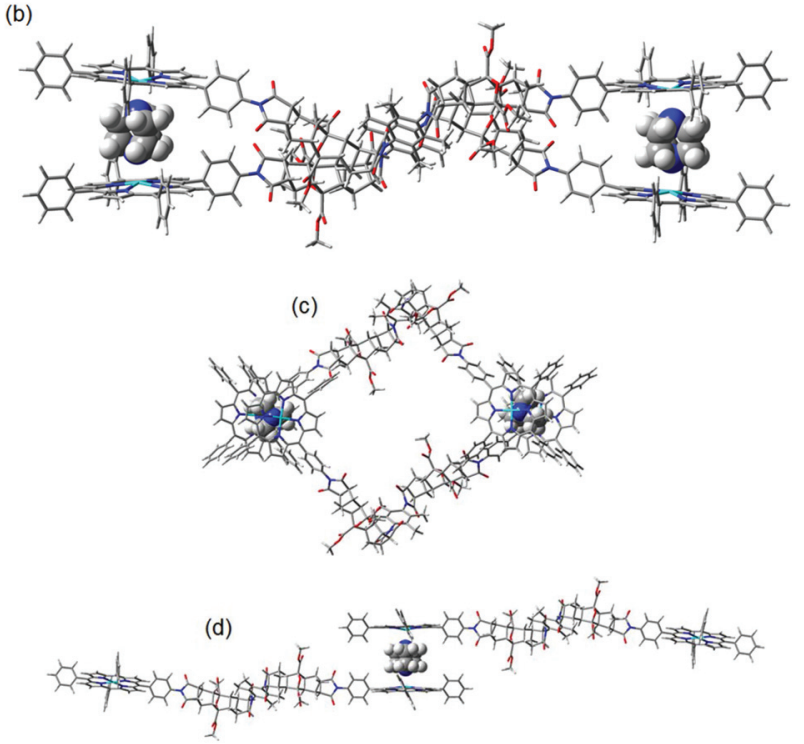

Fig. 19 Equilibrium geometry (semi-empirical, AM1) of (a)-(c) different orientations of anti-(3b) $)_{2} \cdot(\mathrm{DABCO})_{2} ;$ (d) $n: n$ polymeric assembly anti$(3 \mathrm{~b})_{n} \cdot(\mathrm{DABCO})_{n}$ (truncated). Image rendered in GaussView. ${ }^{116}$

partially distorted from planarity,\|\| as was observed experimentally in the X-ray crystallographic structures of related compound 11 (Fig. 6). Overlay of the polycyclic arms in models with and without DABCO (not shown) revealed only minimal

|| || While the 2,3,5,6-tetramethylphenyl diimide group is distorted from planarity, no curvature was observed along the norbornyl diimide plane. A degree of curvature was observed in the analogous model of the freely rotating tweezer with guest, 1·DABCO. ${ }^{90}$ distortion, providing further evidence that the polycyclic arms are essentially rigid. The overall complexed structure does not appear to be significantly strained, and this supports the high association constant that has been determined experimentally.

The anti-(3b) $)_{2} \cdot(\mathrm{DABCO})_{2}$ complex could exist in several molecular orientations, for example where the polycyclic linkers are stacked horizontally, vertically, or adopt a four sided structure (Fig. 19(a)-(c) respectively). In addition, the $n: n$ polymeric assembly, anti-(3b $)_{n} \cdot(\mathrm{DABCO})_{n}$, is shown in Fig. 19(d), truncated to show a single repeating unit. No further investigation has been conducted into the identity of the several sandwich species observed during the NMR titration of anti-3b with DABCO.

\section{Conclusions}

The degree of rotation in our tweezer architecture was restricted from freely rotating by fully substituting the phenyl diimide linker core with methyl groups. Evidence of restricted rotation preventing interconversion between the syn- and anticonformations was provided by UV/Vis and NMR spectroscopy, host-guest complexation models and speciation, and X-ray crystallography.

UV/Vis and NMR titration confirmed that complexation between syn-3a and DABCO is best described by a 3a-DABCO and $3 \mathbf{a} \cdot(\mathrm{DABCO})_{2}$ complexation model. The large association constant obtained for syn-3a-DABCO $\left(K_{11}=1.25 \times 10^{8} \mathrm{M}^{-1}\right)$ indicates the tweezer is sufficiently preorganised for DABCO. This is a similar outcome to freely rotating $\mathbf{1} \cdot \mathrm{DABCO}\left(K_{11}=\right.$ $8.1 \times 10^{7} \mathrm{M}^{-1}$ (ref. 15)), which is also sufficiently preorganised for DABCO. The microscopic effective molarity, ${ }^{117-119}$ EM (divided by the statistical factor, $K_{\sigma}$ ), was calculated to be $9.76 \times 10^{-4} \mathrm{M}$ for syn-3a-DABCO $\left(K_{\sigma}=8\right), 6.33 \times 10^{-4} \mathrm{M}$ for freely rotating 1.DABCO $\left(K_{\sigma}=8\right)$, and $1.70 \times 10^{-5} \mathrm{M}$ for anti- $(3 \mathbf{b})_{2} \cdot(\mathrm{DABCO})_{2}$ $\left(K_{\sigma}=128\right)(\mathrm{S} 25 \dagger)$. Effective molarity values of other porphyrin host-guest systems in the literature usually range between $10^{-3}-10^{1} \mathrm{M},{ }^{10,59,106,107,109,118 * * *}$ although larger values have been reported. ${ }^{11,119}$ Further work is underway in our laboratory to examine the difference in preorganisation between $\operatorname{syn}$-3a and freely rotating $\mathbf{1}$, which is expected to be manifested for ligands with length much greater than DABCO $(2.64 \AA)$ where the required interporphyrin distance for guest complexation requires significant rotation through the phenyl diimide linker core. Molecular modelling of syn-3a-DABCO suggests that the interporphyrin distance is modulated by partial rotation of the polycyclic scaffold about the 2,3,5,6-tetramethylphenyl diimide core, with the polycyclic scaffold remaining rigid. Nevertheless, the combined results of both this manuscript

\footnotetext{
*** Effective molarity is sometimes reported as the microscopic effective molarity multiplied by the statistical factor, $K_{\sigma} \cdot{ }^{117-119}$ Our $K_{\sigma} \cdot$ EM values are $7.81 \times 10^{-3} \mathrm{M}$ for syn-3a-DABCO, $5.06 \times 10^{-3} \mathrm{M}$ for freely rotating $1 \cdot \mathrm{DABCO}$, and $2.18 \times 10^{-3} \mathrm{M}$ for anti-(3b $)_{2} \cdot(\mathrm{DABCO})_{2}$. Additionally, the determination of $K_{\sigma}$ sometimes varies, ${ }^{128}$ which can influence the statistically corrected microscopic effective molarity.
} 
and our previous work ${ }^{15}$ are in agreement with the concept that the linker need only confer the system with moderate or sufficient preorganisation to obtain a large association constant that is enhanced compared to the reference monomeric complex.§

As expected, the UV/Vis and NMR titrations of anti-3b with DABCO confirmed its non-tweezer like behaviour compared to syn-3a, and was best described by a $(\mathbf{3 b})_{2} \cdot(\mathrm{DABCO})_{2}$ and 3b-(DABCO $)_{2}$ complexation model. The NMR data indicated the formation of major and minor sandwich species, most likely different orientations of anti-(3b $)_{2} \cdot(\mathrm{DABCO})_{2}$, or $n: n$ polymeric anti-(3b)$\cdot(\mathrm{DABCO})_{n}$, as represented by molecular modelling.

\section{Experimental}

\section{Molecular modelling}

Molecular modelling was undertaken using the Wavefunction Spartan '10 software package. ${ }^{93}$ Equilibrium geometry energy minimisation was calculated using a semi-empirical AM1 model.

\section{Characterisation}

Melting points were measured using a Barloworld Scientific SMP10 melting point apparatus. Theoretical mass spectra were generated by using the mMass software package. ${ }^{120}$

NMR spectra were recorded on a Bruker UltraShield Avance III $600 \mathrm{MHz}$ NMR Spectrometer running the TopSpin software package at $293 \mathrm{~K}\left(20{ }^{\circ} \mathrm{C}\right)$. Spectra were calibrated to the residual solvent signal. ${ }^{121} \mathrm{CDCl}_{3}$ was deacidified by passing through neutral activated aluminium oxide (Scharlau, activity degree 1, 70-290 mesh, grain size 0.05-0.2 $\mathrm{mm}$ ) and stored under a nitrogen atmosphere over silver foil/molecular sieves in a brown glass bottle.

X-ray diffraction intensity data for compounds $\mathbf{1 1 a}$ and $\mathbf{1 1 b}$ was collected with an Oxford Diffraction SuperNova CCD diffractometer using $\mathrm{Cu}-\mathrm{K} \alpha$ radiation. The temperature during data collection was maintained at $130.00(10)$ using an Oxford Cryosystems cooling device. The structure was solved by direct methods and difference Fourier synthesis. ${ }^{122}$ Thermal ellipsoid plots were generated using the program ORTEP- ${ }^{123}$ integrated within the WINGX ${ }^{124}$ suite of programs. Additional information on the crystal structures of compounds 11a and 11b can be found in the ESI (see S18 and S21†). CCDC 1526930-1526931† contain the supplementary crystallographic data for this paper.

$\mathrm{UV} / \mathrm{Vis}$ spectra were recorded on a Cary 50 instrument at $20{ }^{\circ} \mathrm{C}$ in a Starna Type $21 \mathrm{SX} 1 \mathrm{~cm}^{2}$ quartz cuvette with the following parameters: average time $0.05 \mathrm{~s}$, data interval $0.15 \mathrm{~nm}$, scan rate $180 \mathrm{~nm} \mathrm{~min}{ }^{-1}$, wavelength range $300-700 \mathrm{~nm}$, baseline correction to blank solvent. Dry $\mathrm{CHCl}_{3}$ for recording spectra was prepared under a nitrogen atmosphere first by reflux over $\mathrm{P}_{2} \mathrm{O}_{5}$ then distillation, ${ }^{125}$ and deacidified and stored the same as above for $\mathrm{CDCl}_{3}$.

\section{Reagents}

Where necessary, solvents and reagents for synthesis were purified according to the methods published. ${ }^{125}$ Dry THF was freshly distilled from sodium/benzophenone, dry $\mathrm{CH}_{2} \mathrm{Cl}_{2}$ freshly distilled from $\mathrm{CaH}_{2}$, and dry DMF and DMSO were distilled under reduced pressure onto fresh molecular sieves after stirring on molecular sieves overnight. The following chemicals were purified by sublimation under high vacuum at $0.17 \mathrm{mmHg}$ at the following temperatures, then stored under a nitrogen atmosphere, protected from light, and in a desiccator at room temperature unless otherwise specified: potassium tert-butoxide at $160{ }^{\circ} \mathrm{C}$, DABCO twice at $75{ }^{\circ} \mathrm{C}$ and stored at -20 ${ }^{\circ} \mathrm{C}$. 2,3,5,6-tetramethyl- $p$-phenylenediamine 5 (SigmaAldrich) was used as purchased.

Silica gel (Davisil, $60 \AA$, 40-63 $\mu \mathrm{m}$, Grace Davison Discovery Sciences) was used for column chromatography. Kieselgel silica gel 60 F254 aluminium sheets (Merck) was used for TLC. Colourless compounds were visualised using a UV lamp or permanganate dip stain.

\section{Methodology for host-guest titrations}

All samples for host-guest titrations were weighed using a five decimal point balance (Shimadzu AUW220D or AandD GR-202). Volumetric glassware (class A) was used for volumes $>1 \mathrm{~mL}$. Gas tight microlitre syringes (SGE, Hamilton) were used for volumes $\leq 1 \mathrm{~mL}$. UV/Vis host-guest titrations were carried out at constant host concentrations of $10^{-6}-10^{-7} \mathrm{M}$ in $\mathrm{CHCl}_{3}$ (absorbance of free host $<1$ absorbance unit). Complexation models, association constants and speciation diagrams were calculated from the UV/Vis titration data using the HypSpec and HySS2009 software packages (Protonic software $)^{104,105}$ over 400-450 nm. A more detailed discussion of examining the fitting can be found in $\mathrm{S} 22 . \dagger^{1} \mathrm{H}$ NMR host-guest titrations were carried out in $\mathrm{CDCl}_{3}$ at non-constant host concentration, starting at $10^{-3}-10^{-4} \mathrm{M}$, and gradually diluted by aliquots of guest solution (usually $5-10 \mu \mathrm{L}$ per 0.1 equivalents of guest). Low temperature NMR was undertaken at -50 to $-60{ }^{\circ} \mathrm{C}$.

\section{General procedure for sealed tube ACE reactions}

An $80 \mathrm{~mL}$ sealed tube (BSG Glassware, Tasmania, screw thread stopper with upper and lower Viton O-rings) was fitted with a stirrer bar and loaded with $0.8 \mathrm{~g}$ combined starting materials suspended in no more than $20 \mathrm{~mL}$ of solvent (less than one quarter total volume of flask). The tube was wrapped in alfoil, immersed in an oil bath relative to the solvent level, and heated to $160{ }^{\circ} \mathrm{C}$ with stirring for 24 hours behind a blast shield. O-rings (Viton) were replaced for each reaction.

\section{General procedure for porphyrin zinc(II) metallation}

Using standard porphyrin zinc(II) metallation conditions, ${ }^{66}$ a solution of $\mathrm{Zn}(\mathrm{OAc})_{2} \cdot 2 \mathrm{H}_{2} \mathrm{O}$ (excess, usually 5-10 eq. per porphyrin) in $\mathrm{MeOH}$ was added dropwise down the condenser to a refluxing solution of porphyrin in $\mathrm{CHCl}_{3}\left(\right.$ or $\left.\mathrm{CH}_{2} \mathrm{Cl}_{2}\right) / \mathrm{MeOH}$ (approx. 4:1), such that the combined volume was $\mathrm{CHCl}_{3} \geq$ $\mathrm{MeOH}$. The solution was refluxed for 1-2 hours, with further 
$\mathrm{CHCl}_{3}$ added during this time as necessary to prevent evaporation to dryness or precipitation of the porphyrin. The mixture was cooled, diluted with $\mathrm{CHCl}_{3}$, washed with $\mathrm{H}_{2} \mathrm{O}$, dried with $\mathrm{Na}_{2} \mathrm{SO}_{4}$, filtered, and the solvent removed in vacuo. The material was purified by column chromatography (silica) and recrystallised from $\mathrm{CDCl}_{3} / \mathrm{MeOH}$ to afford purple crystals.

\section{Synthesis of compounds and characterisation data}

endo-Linker (mixture of syn-6a + anti-6b). A solution of endocyclobutene diester anhydride $4^{15,55}(3.73 \mathrm{~g}, 12.2 \mathrm{mmol})$ and 2,3,5,6-tetramethyl-p-phenylenediamine 5 (1.0 g, $6.1 \mathrm{mmol}$, 0.5 eq.) in degassed dry DMSO $(60 \mathrm{~mL})$ was heated at $80{ }^{\circ} \mathrm{C}$ under an argon atmosphere for 1 day. The DMSO was removed by distillation under reduced pressure, the mixture redissolved in $\mathrm{Ac}_{2} \mathrm{O}(80 \mathrm{~mL})$, NaOAc $(7.2 \mathrm{~g}, 53 \mathrm{mmol})$ added, and the solution heated at $80{ }^{\circ} \mathrm{C}$ under a nitrogen atmosphere for a further 1 day, after which a precipitate was observed. Preliminary ${ }^{1} \mathrm{H}$ NMR of the reaction mixture suggested two isomers in an approximately 60:40 ratio (although may be due to different solubility), distinguished by outer and inner pairs of non-equivalent $\mathrm{CH}_{3}$ phenyl substituent resonances. The precipitate was removed by filtration and the solids redissolved in $\mathrm{CHCl}_{3}$ (200 mL), washed with $\mathrm{H}_{2} \mathrm{O}(2 \times 200 \mathrm{~mL})$, aqueous $\mathrm{NaOH}$ solution $(2 \mathrm{M}, 3 \times 200 \mathrm{~mL})$, aqueous $\mathrm{HCl}$ solution $(2 \mathrm{M}, 1 \times$ $100 \mathrm{~mL}), \mathrm{H}_{2} \mathrm{O}(1 \times 100 \mathrm{~mL})$, dried $\left(\mathrm{Na}_{2} \mathrm{SO}_{4}\right)$, and the solvent removed in vacuo to afford a white powder $(3.25 \mathrm{~g}, 72 \%$, m.p. > $300{ }^{\circ} \mathrm{C}$ ). The linker was used as a mixture due to difficulty in separation of the isomers.

A small sample of the isomers was separated by column chromatography, using either of the following methods or a combination of both. Method A: silica $\left(10 \% \mathrm{THF} / \mathrm{CHCl}_{3}\right)$ to partially resolve isomers, if bands co-elute then silica $(5 \%$ $\mathrm{MeOH} / \mathrm{CHCl}_{3}$ ), followed by recrystallisation from $\mathrm{CHCl}_{3} /$ $\mathrm{MeOH}$, solids washed with $\mathrm{MeOH}$. Method B: silica plug (EtOAc), then silica (load $\mathrm{CHCl}_{3}$, elute $50 \% \mathrm{EtOAc} / \mathrm{CHCl}_{3}$, poor solubility and precipitation on column). Unfortunately the assignment of each isomer as either syn- or anti-could not be achieved by ${ }^{1} \mathrm{H}$ NOE spectroscopy, and so are referred to by the inner and outer $\mathrm{CH}_{3}$ isomer nomenclature established above.

Inner $\mathrm{CH}_{3}$ isomer. ${ }^{1} \mathrm{H} \mathrm{NMR}\left(600 \mathrm{MHz}, 20{ }^{\circ} \mathrm{C}, \mathrm{CDCl}_{3}\right): 3.80(\mathrm{~s}$, 12H), 3.50-3.47 (m, 4H), $3.11(\mathrm{~s}, 4 \mathrm{H}), 2.98-2.95(\mathrm{~m}, 4 \mathrm{H}), 2.07$ $(\mathrm{s}, 6 \mathrm{H}), 1.95(\mathrm{~s}, 6 \mathrm{H}), 1.86(\mathrm{~d}, J=11.6 \mathrm{~Hz}, 2 \mathrm{H}), 1.59(\mathrm{~d}, J=$ $11.6 \mathrm{~Hz}, 2 \mathrm{H}) .{ }^{13} \mathrm{C} \mathrm{NMR}\left(150 \mathrm{MHz}, \mathrm{CDCl}_{3}\right)$ : 175.72, 160.80, 141.45, 133.16, 132.62, 132.04, 52.27, 48.16, 43.15, 36.53, 34.83, 16.18, 15.51. HRMS (ESI-TOF-MS) for $\mathrm{C}_{40} \mathrm{H}_{40} \mathrm{~N}_{2} \mathrm{O}_{12} \mathrm{Na}^{+}$ $[\mathrm{M}+\mathrm{Na}]^{+}$: calc.: 763.2479. Found: 763.2494.

Outer $\mathrm{CH}_{3}$ isomer. ${ }^{1} \mathrm{H}$ NMR (600 MHz, $\left.20{ }^{\circ} \mathrm{C}, \mathrm{CDCl}_{3}\right): 3.80(\mathrm{~s}$, 12H), 3.50-3.46 (m, 4H), $3.12(\mathrm{~s}, 4 \mathrm{H}), 2.98-2.96(\mathrm{~m}, 4 \mathrm{H}), 2.09$ (s, 6H), $1.94(\mathrm{~s}, 6 \mathrm{H}), 1.86(\mathrm{~d}, J=11.5 \mathrm{~Hz}, 2 \mathrm{H}), 1.59(\mathrm{~d}, J=$ $11.5 \mathrm{~Hz}, 2 \mathrm{H}) .{ }^{13} \mathrm{C} \mathrm{NMR}\left(150 \mathrm{MHz}, \mathrm{CDCl}_{3}\right)$ : 175.74, 160.79, $141.45,133.11,132.71,132.03,52.27,48.18,43.15$, 36.55, 34.84, 16.17, 15.58. HRMS (ESI-TOF-MS) for $\mathrm{C}_{40} \mathrm{H}_{40} \mathrm{~N}_{2} \mathrm{O}_{12} \mathrm{Na}^{+}$ $[\mathrm{M}+\mathrm{Na}]^{+}$: calc.: 763.2479. Found: 763.2494.

endo-Bis-epoxide linker (syn- + anti-mixture 7). endoMitsudo linker (mixture of $6 \mathbf{a}+6 \mathbf{b})(1.50 \mathrm{~g}, 2.0 \mathrm{mmol})$ was dissolved in dry $\mathrm{CH}_{2} \mathrm{Cl}_{2}(75 \mathrm{~mL})$ under a nitrogen atmosphere and cooled to $0{ }^{\circ} \mathrm{C}$. Anhydrous tert-butyl hydroperoxide in toluene $^{126}$ (3.3 M, $1.53 \mathrm{~mL}, 5.1 \mathrm{mmol}, 2.5$ eq.) was added and stirred for a further $10 \mathrm{~min}$ at $0{ }^{\circ} \mathrm{C}$, after which sublimed potassium tert-butoxide $(0.23 \mathrm{~g}, 2.0 \mathrm{mmol}, 1 \mathrm{eq}$. $)$ was added. The mixture was allowed to warm to room temperature over 30 minutes, and after stirring at room temperature for a further 3 hours, the mixture was diluted with $\mathrm{CH}_{2} \mathrm{Cl}_{2}(50 \mathrm{~mL})$ and sodium sulfite $(10 \%$ aqueous solution, $10 \mathrm{~mL})$ added with vigorous stirring for 15 minutes. The mixture was further diluted with $\mathrm{CHCl}_{3}(1 \mathrm{~L})$, washed with brine $(500 \mathrm{~mL})$, dried with $\mathrm{Na}_{2} \mathrm{SO}_{4}$, filtered, and the solvent removed in vacuo. NMR of the reaction mixture indicated approximately $50 \%$ remaining starting material, and so the reaction was repeated on this mixture using the same quantities of epoxidation reagents (for later repeats of this reaction, the epoxidation reagent quantity was doubled from the beginning). This afforded a white powder $(0.80 \mathrm{~g}, 51 \%)$, used in subsequent reactions without further purification and as a mixture of isomers. A sample was recrystallised from $\mathrm{CHCl}_{3} /$ hexane for $\mathrm{MS}$ and melting point analysis (mixture of isomers). M.p. > 250-300 ${ }^{\circ} \mathrm{C}$ (decomposition). $\left.{ }^{1} \mathrm{H} \mathrm{NMR} \mathrm{(600} \mathrm{MHz,} 20{ }^{\circ} \mathrm{C}, \mathrm{CDCl}_{3}\right)$ : as mixture of isomers $3.82(\mathrm{~s}, 12 \mathrm{H}), 3.46-3.41(\mathrm{~m}, 8 \mathrm{H}), 2.74-2.70(\mathrm{~m}, 4 \mathrm{H})$, $2.24(\mathrm{~d}, J=11.2 \mathrm{~Hz}, 2 \mathrm{H}), 2.03$ (a) +2.00 (b) (singlets, combined integration 6H), 1.92 (b) +1.89 (a) (singlets, combined integration $6 \mathrm{H}$ ), 1.84 (d, $J=11.2 \mathrm{~Hz}, 2 \mathrm{H})$. HRMS (ESI-TOF-MS) for $\mathrm{C}_{40} \mathrm{H}_{40} \mathrm{~N}_{2} \mathrm{O}_{14} \mathrm{Na}^{+}[\mathrm{M}+\mathrm{Na}]^{+}$: calc.: 795.2377. Found: 795.2393.

Free base tweezer (mixture of $\boldsymbol{s y n}-\mathbf{9 a}+\boldsymbol{a n t i - 9 b )}$. A suspension of endo-bis-epoxide linker mixture $7(0.2 \mathrm{~g}, 0.26 \mathrm{mmol})$ and exo-imide porphyrin receptor $8(0.4 \mathrm{~g}, 0.52 \mathrm{mmol}, 2 \mathrm{eq}$.) in dry THF $(10 \mathrm{~mL})$ was heated in a sealed tube at $160{ }^{\circ} \mathrm{C}$ for 20-24 hours using the general procedure specified above. This procedure was repeated several times on a similar scale until $1.0 \mathrm{~g}$ epoxide had been reacted. The material from each reaction was combined. The solvent was removed in vacuo and the material purified by column chromatography (silica, 10\% $\mathrm{THF} / \mathrm{CH}_{2} \mathrm{Cl}_{2}$ ), recovering exo-imide porphyrin receptor 8 in the first major porphyrin band. The subsequent two closely eluting porphyrin bands each contained a majority of each isomer, and each isomer was resubjected to column chromatography to further improve separation. Isomers could be speculated as syn- and anti- on the basis of desymmetrisation of the porphyrin aromatic resonances (significant for syn-) and quantified by the difference in relative integrations of the inner pyrrole resonances. This afforded a purple powder (combined isomer mass $0.68 \mathrm{~g}, 23 \%=10 \%$ syn- $+13 \%$ anti-). The antiisomer was isolated completely free of syn-, while the synisomer contained approx. 25\% residual anti-. Each isomer was crudely recrystallised from $\mathrm{CDCl}_{3} / \mathrm{MeOH}$, however, further purification (particularly removal of the anti-9b isomer from the syn-9a sample) was carried out post-zinc(II) metalation in an effort to conserve product.

anti-9b. ${ }^{1} \mathrm{H}$ NMR (600 MHz, $\left.20{ }^{\circ} \mathrm{C}, \mathrm{CDCl}_{3}\right)$ : $8.85(\mathrm{~s}, 16 \mathrm{H})$, $8.30(\mathrm{~d}, J=8.1 \mathrm{~Hz}, 4 \mathrm{H}), 8.25-8.18(\mathrm{~m}, 12 \mathrm{H}), 7.82-7.73(\mathrm{~m}$, $18 \mathrm{H}), 7.62(\mathrm{~d}, J=8.1 \mathrm{~Hz}, 4 \mathrm{H}), 3.98(\mathrm{~s}, 12 \mathrm{H}), 3.34-3.30(\mathrm{~m}, 4 \mathrm{H})$, $2.92(\mathrm{~s}, 4 \mathrm{H}), 2.90(\mathrm{~s}, 4 \mathrm{H}), 2.85-2.82(\mathrm{~m}, 4 \mathrm{H}), 2.76(\mathrm{~d}, J=10.9$ $\mathrm{Hz}, 2 \mathrm{H}), 2.58-2.51$ ( $\mathrm{m}, 6 \mathrm{H}$, two overlapping signals), 2.32 (s, 
$4 \mathrm{H}), 2.28(\mathrm{~s}, 6 \mathrm{H}), 2.04(\mathrm{~s}, 6 \mathrm{H}), 1.41(\mathrm{~d}, J=10.9 \mathrm{~Hz}, 2 \mathrm{H}), 1.22(\mathrm{~d}$, $J=11.9 \mathrm{~Hz}, 2 \mathrm{H}),-2.80(\mathrm{~s}, 4 \mathrm{H})$.

syn-9a. Characterised as the zinc(II) derivative. ${ }^{1} \mathrm{H}$ NMR spectrum provided in $\mathrm{S} 8 \dagger$ as mixture with anti-9b.

HRMS (ESI-TOF-MS) for two samples containing different ratios of syn-9a/anti-9b. Sample $1\left[\mathrm{C}_{146} \mathrm{H}_{116} \mathrm{~N}_{12} \mathrm{O}_{18}\right]^{2+}[\mathrm{M}+$ $2 \mathrm{H}]^{2+}$ : calc.: 1162.4260. Found: 1162.4267. Sample 2 $\left[\mathrm{C}_{146} \mathrm{H}_{114} \mathrm{~N}_{12} \mathrm{O}_{18} \mathrm{Na}_{2}\right]^{2+}[\mathrm{M}+2 \mathrm{Na}]^{2+}$ : calc.: 1184.4079 . Found: 1184.4110.

syn-Zinc(II) tweezer, 3a. $\mathrm{Zn}(\mathrm{OAc})_{2} \cdot 2 \mathrm{H}_{2} \mathrm{O}(1.0 \mathrm{~g}, 4.55 \mathrm{mmol})$ in $\mathrm{MeOH}(10 \mathrm{~mL})$ was heated under reflux with syn-9a (mixture with $25 \%$ anti-9b, $0.37 \mathrm{~g}, 0.16 \mathrm{mmol})$ in $\mathrm{CH}_{2} \mathrm{Cl}_{2}(20 \mathrm{~mL})$, during which the solution developed a green/blue hue, and was worked up according to the general procedure above. The product was purified by column chromatography to remove the green/blue impurity (silica, $10 \% \mathrm{THF} / \mathrm{CHCl}_{3}$ ) collecting the strong porphyrin band. The solvent was removed in vacuo to afford a purple powder $(0.31 \mathrm{~g}, 79 \%)$, in which remained $33 \%$ anti-isomer (determined by relative NMR integration). This material was recrystallised repeatedly from $\mathrm{CHCl}_{3} / \mathrm{MeOH}$ until free of the anti-isomer (approximately three to four times), to afford bright purple crystals for host-guest titrations. ${ }^{1} \mathrm{H}$ NMR (600 MHz, $20{ }^{\circ} \mathrm{C}, \mathrm{CDCl}_{3}$, approx. $1 \mathrm{mM}$, concentration dependent): 8.93-8.84 (m, 16H), 8.23-8.16 (m, 8H), 8.14-8.09 (m, $8 \mathrm{H}), 7.78-7.70(\mathrm{~m}, 6 \mathrm{H}), 7.66-7.60(\mathrm{~m}, 12 \mathrm{H}), 7.48-7.38$ (bs, $4 \mathrm{H})$, $3.98(\mathrm{~s}, 12 \mathrm{H}), 3.33(\mathrm{~m}, 4 \mathrm{H}), 2.88-2.83(\mathrm{~m}, 8 \mathrm{H}), 2.81(\mathrm{~s}, 4 \mathrm{H})$, 2.77 (d, $J=11.1 \mathrm{~Hz}, 2 \mathrm{H}), 2.56(\mathrm{~s}, 4 \mathrm{H}), 2.49$ (d, $J=11.9 \mathrm{~Hz}, 2 \mathrm{H})$, $2.33(\mathrm{~s}, 4 \mathrm{H}), 2.31(\mathrm{~s}, 6 \mathrm{H}), 2.00(\mathrm{~s}, 6 \mathrm{H}), 1.43(\mathrm{~d}, J=11.1 \mathrm{~Hz}, 2 \mathrm{H})$, $1.13(\mathrm{~d}, J=11.9 \mathrm{~Hz}, 2 \mathrm{H})$. UV/Vis $\left(\mathrm{CHCl}_{3}\right): \lambda_{\max }(\mathrm{nm})=418.4$ (shoulder around 400), 547.3, 583.9, $\varepsilon_{\text {single porphyrin }}=4.9 \times 10^{5}$ $\mathrm{L} \mathrm{mol}^{-1} \mathrm{~cm}^{-1}$. HRMS (MALDI-TOF) for $\mathrm{C}_{146} \mathrm{H}_{110} \mathrm{~N}_{12} \mathrm{O}_{18} \mathrm{Zn}_{2}$ $[\mathrm{M}]^{\circ+}$ : calc.: 2446.664 (monoisotopic). Found: 2446.694.

anti-Zinc(II) tweezer, 3b. $\mathrm{Zn}(\mathrm{OAc})_{2} \cdot 2 \mathrm{H}_{2} \mathrm{O}(1.0 \mathrm{~g}, 4.55 \mathrm{mmol})$ in $\mathrm{MeOH}(10 \mathrm{~mL})$ was heated under reflux with anti-9b $(0.31 \mathrm{~g}$, $0.13 \mathrm{mmol})$ in $\mathrm{CH}_{2} \mathrm{Cl}_{2}(20 \mathrm{~mL})$ and worked up according to the general procedure above. The product was purified by column chromatography (silica, $10 \% \mathrm{THF} / \mathrm{CHCl}_{3}$ ) collecting the strong porphyrin band. The solvent was removed in vacuo to afford a purple powder $(0.29 \mathrm{~g}, 89 \%)$, which was recrystallised from $\mathrm{CHCl}_{3} / \mathrm{MeOH}$ to afford bright purple crystals (free from synisomer) for host-guest titrations. ${ }^{1} \mathrm{H}$ NMR $\left(600 \mathrm{MHz}, 20{ }^{\circ} \mathrm{C}\right.$, $\mathrm{CDCl}_{3}$, approx. $\left.0.85 \mathrm{mM}\right)$ : 8.97-8.94 (m, 16H), $8.31(\mathrm{~d}, J=$ $8.2 \mathrm{~Hz}, 4 \mathrm{H}), 8.24-8.20(\mathrm{~m}, 12 \mathrm{H}), 7.81-7.73(\mathrm{~m}, 18 \mathrm{H}), 7.61$ (d, $J=8.2 \mathrm{~Hz}, 4 \mathrm{H}), 3.98(\mathrm{~s}, 12 \mathrm{H}), 3.33(\mathrm{~m}, 4 \mathrm{H}), 2.91(\mathrm{~s}, 4 \mathrm{H}), 2.89(\mathrm{~s}$, $4 \mathrm{H}), 2.84(\mathrm{~m}, 4 \mathrm{H}), 2.77$ (d, $J=10.8 \mathrm{~Hz}, 2 \mathrm{H}), 2.58-2.50(\mathrm{~m}, 6 \mathrm{H}$, two overlapping signals), $2.32(\mathrm{~s}, 4 \mathrm{H}), 2.28(\mathrm{~s}, 6 \mathrm{H}), 2.04(\mathrm{~s}, 6 \mathrm{H})$, $1.42(\mathrm{~d}, J=10.8 \mathrm{~Hz}, 2 \mathrm{H}), 1.22(\mathrm{~d}, J=12.2 \mathrm{~Hz}, 2 \mathrm{H})$. UV/Vis $\left(\mathrm{CHCl}_{3}\right): \lambda_{\max }(\mathrm{nm})=399.2$ (shoulder), 419.3, 547.4, 585.8, $\varepsilon_{\text {single porphyrin }}=5.8 \times 10^{5} \mathrm{~L} \mathrm{~mol}^{-1} \mathrm{~cm}^{-1}$. HRMS (MALDI-TOF) for $\mathrm{C}_{146} \mathrm{H}_{110} \mathrm{~N}_{12} \mathrm{O}_{18} \mathrm{Zn}_{2}[\mathrm{M}]^{\cdot+}$ : calc.: 2446.6644 (monoisotopic). Found: 2446.6770 .

exo-Linker analogues (syn-11a + anti-11b). A solution of cis5-norbornene-exo-2,3-dicarboxylic anhydride ${ }^{127}(3.0 \mathrm{~g}$, $18.3 \mathrm{mmol}$ ) and 2,3,5,6-tetramethyl-p-phenylenediamine $\mathbf{5}$ (1.5 g, $9.1 \mathrm{mmol}, 0.5$ eq.) in degassed dry DMF (50 mL) was heated at $80{ }^{\circ} \mathrm{C}$ under an argon atmosphere for 3 days, during which a white precipitate formed. The mixture was filtered, washed with hexane, the solid redissolved in $\mathrm{Ac}_{2} \mathrm{O}(50 \mathrm{~mL})$, NaOAc (5.0 g, $36.7 \mathrm{mmol}$ ) added, and the mixture heated at $80{ }^{\circ} \mathrm{C}$ under a nitrogen atmosphere for a further 3 days. Any precipitate was removed by filtration, and the precipitate and $\mathrm{Ac}_{2} \mathrm{O}$ filtrate separately purified. The precipitate was washed with hexane $(2 \times 100 \mathrm{~mL})$, redissolved in $\mathrm{CHCl}_{3}(100 \mathrm{~mL})$, washed with $\mathrm{H}_{2} \mathrm{O}(2 \times 100 \mathrm{~mL})$, dried with $\mathrm{Na}_{2} \mathrm{SO}_{4}$, and the solvent removed in vacuo to afford a solid. For the $\mathrm{Ac}_{2} \mathrm{O}$ filtrate, the $\mathrm{Ac}_{2} \mathrm{O}$ was removed by distillation under reduced pressure, the solid washed with hexane $(2 \times 100 \mathrm{~mL})$, redissolved in $\mathrm{CHCl}_{3}(100 \mathrm{~mL})$, washed with $\mathrm{H}_{2} \mathrm{O}(2 \times 100 \mathrm{~mL})$, dried with $\mathrm{Na}_{2} \mathrm{SO}_{4}$, and the solvent removed in vacuo to afford a solid. ${ }^{1} \mathrm{H}$ NMR of the filtrate and precipitate show that each contains a majority of the opposite isomer, syn- or anti-, distinguished by outer and inner pairs of non-equivalent $\mathrm{CH}_{3}$ phenyl substituent resonances. Additionally, X-ray crystallographic analysis of crystals from both the filtrate and precipitate fractions enabled assignment of the syn- and anti-isomers.

syn-11a (filtrate, outer $\mathrm{CH}_{3}$ ). M.p. $>300{ }^{\circ} \mathrm{C}$ (crystals crack, partial decomposition). ${ }^{1} \mathrm{H}$ NMR $\left(600 \mathrm{MHz}, 20^{\circ} \mathrm{C}, \mathrm{CDCl}_{3}\right): 6.34$ $(\mathrm{m}, 4 \mathrm{H}), 3.42(\mathrm{~m}, 4 \mathrm{H}), 2.91(\mathrm{~s}, 4 \mathrm{H}), 2.051(\mathrm{~s}, 6 \mathrm{H}), 1.967(\mathrm{~s}, 6 \mathrm{H})$, $1.68(\mathrm{~m}, 4 \mathrm{H}) .{ }^{13} \mathrm{C} \mathrm{NMR}\left(150 \mathrm{MHz}, \mathrm{CHCl}_{3}\right):$ 176.72, 138.03, 133.08, 132.67, 131.86, 48.47, 45.29, 43.80, 15.90, 15.63. HRMS (ESI-TOF-MS) for $\mathrm{C}_{28} \mathrm{H}_{28} \mathrm{~N}_{2} \mathrm{O}_{4} \mathrm{Na}^{+}[\mathrm{M}+\mathrm{Na}]^{+}$: calc.: 479.1947 . Found: 479.1957. Single crystal for X-ray diffraction analysis was grown from $\mathrm{CH}_{3} \mathrm{CN}$ by slow evaporation. CCDC $1526930 \dagger$ contains the supplementary crystallographic data for this paper.

anti-11b (precipitate, inner $\mathrm{CH}_{3}$ ). M.p. > $300{ }^{\circ} \mathrm{C}$ (crystals transition from clear to white $195-205{ }^{\circ} \mathrm{C}$, partial decomposition by $\left.300{ }^{\circ} \mathrm{C}\right) .{ }^{1} \mathrm{H}$ NMR (600 MHz, $\left.20{ }^{\circ} \mathrm{C}, \mathrm{CDCl}_{3}\right): 6.34(\mathrm{~m}, 4 \mathrm{H})$, $3.42(\mathrm{~m}, 4 \mathrm{H}), 2.91(\mathrm{~s}, 4 \mathrm{H}), 2.039(\mathrm{~s}, 6 \mathrm{H}), 1.973(\mathrm{~s}, 6 \mathrm{H}), 1.67(\mathrm{~m}$, $4 \mathrm{H}) .{ }^{13} \mathrm{C} \mathrm{NMR}\left(150 \mathrm{MHz}, \mathrm{CHCl}_{3}\right): 176.70,138.01,133.14$, 132.58, 131.84, 48.46, 45.28, 43.78, 15.99, 15.50. HRMS (ESI-TOF-MS) for $\mathrm{C}_{28} \mathrm{H}_{28} \mathrm{~N}_{2} \mathrm{O}_{4} \mathrm{Na}^{+}[\mathrm{M}+\mathrm{Na}]^{+}$: calc.: 479.1947 . Found: 479.1949. Single crystal for X-ray diffraction analysis was grown from $\mathrm{CH}_{3} \mathrm{CN}$ by slow evaporation, and solved as the structure co-crystallised with approx. 6\% mono-epoxide (at the norbornene). CCDC $1526931 \dagger$ contains the supplementary crystallographic data for this paper.

\section{Conflicts of interest}

There are no conflicts to declare.

\section{Acknowledgements}

R. B. M wishes to thank Flinders University for the provision of an Australian Postgraduate Award and the Playford Memorial Trust for a PhD top-up scholarship. R. B. M also thanks the following for their efforts and expertise in accurate mass spectrometry: Dr Sally Duck (Monash University) porphyrin compound 9, Dr Craig Brinkworth (Defence Science 
and Technology Group, Australia) porphyrin compounds syn3a and anti-3b, Dr Daniel Jardine (Flinders Analytical) all other compounds.

\section{Notes and references}

1 J. W. Steed and J. L. Atwood, Supramolecular Chemistry, John Wiley \& Sons, Ltd, 1st edn, 2000.

2 D. Cram, Science, 1988, 240, 760-767.

3 D. J. Cram, G. M. Lein, T. Kaneda, R. C. Helgeson, C. B. Knobler, E. Maverick and K. N. Trueblood, J. Am. Chem. Soc., 1981, 103, 6228-6232.

4 V. Valderrey, G. Aragay and P. Ballester, Coord. Chem. Rev., 2014, 258-259, 137-156.

5 S. Otto, Dalton Trans., 2006, 2861-2864.

6 N. Voyer and F. Maltais, Adv. Mater., 1993, 5, 568-570.

7 S. P. Gaynor, M. J. Gunter, M. R. Johnston and R. N. Warrener, Org. Biomol. Chem., 2006, 4, 2253-2266.

8 M. Nakash and J. K. M. Sanders, J. Org. Chem., 2000, 65, 7266-7271.

9 Z. Rodriguez-Docampo, E. Eugenieva-Ilieva, C. Reyheller, A. M. Belenguer, S. Kubik and S. Otto, Chem. Commun., 2011, 47, 9798-9800.

10 H. Sun, C. A. Hunter and E. M. Llamas, Chem. Sci., 2015, 6, 1444-1453.

11 L. Pengpeng, P. Neuhaus, D. V. Kondratuk, T. S. Balaban and H. L. Anderson, Angew. Chem., Int. Ed., 2014, 53, 7770-7773.

12 N. Solladié, S. Bouatra, R. Rein and J. Roeser, J. Porphyrins Phthalocyanines, 2005, 9, 779-787.

13 N. Solladié, F. Aziat, S. Bouatra and R. Rein, J. Porphyrins Phthalocyanines, 2008, 12, 1250-1260.

14 S. Merkas, S. Bouatra, R. Rein, I. Piantanida, M. Zinic and N. Solladié, J. Porphyrins Phthalocyanines, 2015, 19, 535-546.

15 R. B. Murphy, D.-T. Pham, S. F. Lincoln and M. R. Johnston, Eur. J. Org. Chem., 2013, 2985-2993.

16 H. L. Anderson, S. Anderson and J. K. M. Sanders, J. Chem. Soc., Perkin Trans. 1, 1995, 2231-2245.

17 J. Etxebarria, A. Vidal-Ferran and P. Ballester, Chem. Commun., 2008, 5939-5941.

18 N. Solladié, N. Aubert, S. Bouatra, C. Bourgogne, F. Bregier, J. Brettar, J.-P. Gisselbrecht, M. Gross, R. Rein, C. Sooambar, V. Troiani and M. Walther, J. Porphyrins Phthalocyanines, 2003, 7, 270-281.

19 M. R. Johnston and D. M. Lyons, Supramol. Chem., 2005, 17, 503-511.

20 D. Kim, S. Lee, G. Gao, H. S. Kang and J. Ko, J. Organomet. Chem., 2009, 695, 111-119.

21 Y. Kubo, Y. Murai, J.-i. Yamanaka, S. Tokita and Y. Ishimaru, Tetrahedron Lett., 1999, 40, 6019-6023.

22 S. Yagi, M. Ezoe, I. Yonekura, T. Takagishi and H. Nakazumi, J. Am. Chem. Soc., 2003, 125, 4068-4069.

23 L. H. Tong, J.-L. Wietor, W. Clegg, P. R. Raithby, S. I. Pascu and J. K. M. Sanders, Chem. - Eur. J., 2008, 14, 3035-3044.
24 C.-H. Lee, H. Yoon and W.-D. Jang, Chem. - Eur. J., 2009, 15, 9972-9976.

25 M. Dudič, P. Lhoták, H. Petříčková, I. Stibor, K. Lang and J. Sýkora, Tetrahedron, 2003, 59, 2409-2415.

26 D. Jokic, Z. Asfari and J. Weiss, Org. Lett., 2002, 4, 21292132.

27 D. Jokic, C. Boudon, G. Pognon, M. Bonin, K. J. Schenk, M. Gross and J. Weiss, Chem. - Eur. J., 2005, 11, 41994209.

28 P. Mondal and S. P. Rath, Isr. J. Chem., 2016, 56, 144-155.

29 M. Blom, S. Norrehed, C.-H. Andersson, H. Huang, M. Light, J. Bergquist, H. Grennberg and A. Gogoll, Molecules, 2016, 21, 16.

30 R. B. Murphy, R. E. Norman, J. M. White, M. V. Perkins and M. R. Johnston, Org. Biomol. Chem., 2016, 14, 87078720.

31 R. N. Warrener, D. N. Butler, W. Y. Liao, I. G. Pitt and R. A. Russell, Tetrahedron Lett., 1991, 32, 1889-1892.

32 R. N. Warrener, I. G. Pitt and D. N. Butler, J. Chem. Soc., Chem. Commun., 1983, 1340-1342.

33 R. N. Warrener, A. C. Schultz, D. N. Butler, S. Wang, I. B. Mahadevan and R. A. Russel, Chem. Commun., 1997, 1023-1024.

34 R. N. Warrener, S. Wang and R. A. Russell, Tetrahedron, 1997, 53, 3975-3990.

35 R. N. Warrener, D. N. Butler, D. Margetic, F. M. Pfeffer and R. A. Russell, Tetrahedron Lett., 2000, 41, 4671-4675.

36 M. Golić, M. R. Johnston, D. Margetić, A. C. Schultz and R. N. Warrener, Aust. J. Chem., 2006, 59, 899-914.

37 D. Margetic, M. R. Johnston, E. R. T. Tiekink and R. N. Warrener, Tetrahedron Lett., 1998, 39, 5277-5280.

38 R. N. Warrener, D. N. Butler, L. Liu, D. Margetic and R. A. Russell, Chem. - Eur. J., 2001, 7, 3406-3414.

39 M. J. Gunter, H. Tang and R. N. Warrener, J. Porphyrins Phthalocyanines, 2002, 6, 673-684.

40 A. M. Napper, I. Read, N. J. Head, A. M. Oliver and M. N. Paddon-Row, J. Am. Chem. Soc., 2000, 122, 5220-5221.

41 N. J. Head, A. M. Oliver, K. Look, N. R. Lokan, G. A. Jones and M. N. Paddon-Row, Angew. Chem., Int. Ed., 1999, 38, 3219-3222.

42 M. J. Shephard and M. N. Paddon-Row, J. Phys. Chem. A, 2000, 104, 11628-11635.

43 M. J. Shephard and M. N. Paddon-Row, J. Phys. Chem. A, 1999, 103, 3347-3350.

44 M. R. Johnston, M. J. Latter and R. N. Warrener, Org. Lett., 2002, 4, 2165-2168.

45 M. Johnston, Molecules, 2001, 6, 406-416.

46 M. R. Johnston, M. J. Latter and R. N. Warrener, Aust. J. Chem., 2001, 54, 633-636.

47 M. D. Johnstone, E. K. Schwarze, J. Ahrens, D. Schwarzer, J. J. Holstein, B. Dittrich, F. M. Pfeffer and G. H. Clever, Chem. - Eur. J., 2016, 22, 10791-10795.

48 M. D. Johnstone, M. Frank, G. H. Clever and F. M. Pfeffer, Eur. J. Org. Chem., 2013, 5848-5853.

49 R. N. Robson and F. M. Pfeffer, Chem. Commun., 2016, 52, 8719-8721. 
50 M. D. Johnstone, E. K. Schwarze, G. H. Clever and F. M. Pfeffer, Chem. - Eur. J., 2015, 21, 3948-3955.

51 A. J. Lowe, B. M. Long and F. M. Pfeffer, Chem. Commun., 2013, 49, 3376-3388.

52 B. M. Long and F. M. Pfeffer, Chem. - Asian J., 2014, 9, 1091-1098.

53 R. N. Robson, B. P. Hay and F. M. Pfeffer, ChemistrySelect, 2017, 2, 4605-4608.

54 G. H. Clever and P. Punt, Acc. Chem. Res., 2017, 50, 22332243.

55 M. Shang, R. N. Warrener, D. N. Butler, Y. Murata and D. Margetić, Mol. Diversity, 2011, 15, 541-560.

56 P. Trošelj, A. Briš, Y. Murata and D. Margetić, Struct. Chem., 2012, 23, 791-799.

57 P. Trošelj, I. Đilović, D. Matković-Čalogović and D. Margetić, J. Heterocycl. Chem., 2013, 50, 83-90.

58 H. Tang, Z. Dong, Z. Merican, D. Margetić, Ž. Marinić, M. J. Gunter, D. Officer, D. N. Butler and R. N. Warrener, Tetrahedron Lett., 2009, 50, 667-670.

59 A. R. Mulholland, P. Thordarson, E. J. Mensforth and S. J. Langford, Org. Biomol. Chem., 2012, 10, 6045-6053.

60 G. Giancane, V. Borovkov, Y. Inoue and L. Valli, J. Colloid Interface Sci., 2012, 385, 282-284.

61 V. V. Borovkov, J. M. Lintuluoto and Y. Inoue, Tetrahedron Lett., 1999, 40, 5051-5054.

62 V. V. Borovkov, J. M. Lintuluoto and Y. Inoue, J. Phys. Chem. B, 1999, 103, 5151-5156.

63 V. V. Borovkov, J. M. Lintuluoto and Y. Inoue, J. Am. Chem. Soc., 2001, 123, 2979-2989.

64 R. N. Warrener, M. R. Johnston and M. J. Gunter, Synlett, 1998, 593-595.

65 R. C. Foitzik, A. Lowe and F. M. Pfeffer, Tetrahedron Lett., 2009, 50, 2583-2584.

66 J.-H. Fuhrhop and K. M. Smith, Laboratory methods in porphyrin and metalloporphyrin research, Elsevier Scientific Pub. Co., 1975.

67 E. Stulz, C. C. Mak and J. K. M. Sanders, J. Chem. Soc., Dalton Trans., 2001, 604-613.

68 M. Kasha, H. R. Rawls and M. A. El-Bayoumi, Pure Appl. Chem., 1965, 11, 371-392.

69 A. Osuka and K. Maruyama, J. Am. Chem. Soc., 1988, 110, 4454-4456.

70 C. A. Hunter, J. K. M. Sanders and A. J. Stone, Chem. Phys., 1989, 133, 395-404.

71 C. K. Chang and I. Abdalmuhdi, J. Org. Chem., 1983, 48, 5388-5390.

72 H. A. Staab and T. Carell, Angew. Chem., Int. Ed. Engl., 1994, 33, 1466-1468.

73 Y. Yu, L. Shi, D. Yang and L. Gan, Chem. Sci., 2013, 4, 814-818.

74 S. Verma and N. Singh, Aust. J. Chem., 1976, 29, 295-300.

75 D. P. Curran, S. Geib and N. DeMello, Tetrahedron, 1999, 55, 5681-5704.

76 K. Tanaka, M. Okano, H. Toshino, H. Kita and K.-I. Okamoto, J. Polym. Sci., Part B: Polym. Phys., 1992, 30, 907-914.
77 Y. Zhang, J. M. Lavin and K. D. Shimizu, J. Am. Chem. Soc., 2009, 131, 12062-12063.

78 D.-S. Choi, Y. S. Chong, D. Whitehead and K. D. Shimizu, Org. Lett., 2001, 3, 3757-3760.

79 Y. Chen, M. D. Smith and K. D. Shimizu, Tetrahedron Lett., 2001, 42, 7185-7187.

80 R. D. Rasberry, X. Wu, B. N. Bullock, M. D. Smith and K. D. Shimizu, Org. Lett., 2009, 11, 2599-2602.

81 C. F. Degenhardt, J. M. Lavin, M. D. Smith and K. D. Shimizu, Org. Lett., 2005, 7, 4079-4081.

82 J. M. Lavin and K. D. Shimizu, Chem. Commun., 2007, 228-230.

83 W. R. Carroll, P. Pellechia and K. D. Shimizu, Org. Lett., 2008, 10, 3547-3550.

84 C. W. Miller, C. E. Hoyle, E. J. Valente, D. H. Magers and E. S. Jönsson, J. Phys. Chem. A, 1999, 103, 6406-6412.

85 K. Kondo, H. Fujita, T. Suzuki and Y. Murakami, Tetrahedron Lett., 1999, 40, 5577-5580.

86 M. Mao, J. England and S. R. Turner, Polymer, 2011, 52, 4498-4502.

87 C. W. Miller, E. S. Jönsson, C. E. Hoyle, K. Viswanathan and E. J. Valente, J. Phys. Chem. B, 2001, 105, 2707-2717.

88 C. Miller, C. Hoyle, E. Valente, J. Zubkowski and E. S. Jönsson, J. Chem. Crystallogr., 2000, 30, 563-571.

89 D. P. Curran and N. C. DeMello, J. Chem. Soc., Chem. Commun., 1993, 1314-1317.

90 R. B. Murphy, PhD thesis, Flinders University, Adelaide, South Australia, 2016.

91 Mercury 3.8, CCDC, 2016, http://www.ccdc.cam.ac.uk/ mercury/.

92 P. D. Bartlett, G. L. Combs, A. X. T. Le, W. H. Watson, J. Galloy and M. Kimura, J. Am. Chem. Soc., 1982, 104, 3131-3138.

93 Spartan '10 for Windows, Wavefunction, Inc., 18401 Von Karman Avenue, Suite 370, Irvine, CA 92612 USA, http:// www.wavefun.com/index.html.

94 B. A. Langowski, R. Rothchild and A.-M. Sapse, Spectrosc. Lett., 2001, 34, 235-251.

95 A. Camara-Campos, C. A. Hunter and S. Tomas, Proc. Natl. Acad. Sci. U. S. A., 2006, 103, 3034-3038.

96 P. N. Taylor and H. L. Anderson, J. Am. Chem. Soc., 1999, 121, 11538-11545.

97 H.-T. Nguyen, D.-T. Pham, C. J. Easton and S. F. Lincoln, Aust. J. Chem., 2013, 66, 1057-1064.

98 E. A. Kataev and T. A. Shumilova, Molecules, 2015, 20, 3354-3370.

99 R. Montis, M. C. Aragoni, M. Arca, C. Bazzicalupi, A. J. Blake, C. Caltagirone, G. De Filippo, A. Garau, P. Gratteri, F. Isaia, V. Lippolis and A. Pintus, Inorg. Chim. Acta, 2012, 381, 170-180.

100 F. Ulatowski, K. Dąbrowa, T. Bałakier and J. Jurczak, J. Org. Chem., 2016, 81, 1746-1756.

101 S. A. Ikbal, S. Brahma and S. P. Rath, Chem. Commun., 2015, 51, 895-898.

102 A. Dhamija, S. A. Ikbal and S. P. Rath, Inorg. Chem., 2016, 55, 13014-13026. 
103 E. A. Kataev, N. Backmann, T. A. Shumilova, T. Rüffer and H. Lang, Supramol. Chem., 2016, 28, 53-61.

104 Protonic Software, 2 Templegate Avenue, Leeds, LS150HD, UK. ( http://www.hyperquad.co.uk).

105 P. Gans, A. Sabatini and A. Vacca, Talanta, 1996, 43, 17391753.

106 P. Ballester, A. Costa, A. M. Castilla, P. M. Deyá, A. Frontera, R. M. Gomilla and C. A. Hunter, Chem. - Eur. J., 2005, 11, 2196-2206.

107 L. Baldini, P. Ballester, A. Casnati, R. M. Gomila, C. A. Hunter, F. Sansone and R. Ungaro, J. Am. Chem. Soc., 2003, 125, 14181-14189.

108 P. Ballester, A. I. Oliva, A. Costa, P. M. Deyà, A. Frontera, R. M. Gomila and C. A. Hunter, J. Am. Chem. Soc., 2006, 128, 5560-5569.

109 H. L. Anderson, Inorg. Chem., 1994, 33, 972-981.

110 C. C. Mak, N. Bampos and J. M. K. Sanders, Angew. Chem., Int. Ed., 1998, 37, 3020-3023.

111 C. A. Hunter, M. N. Meah and J. K. M. Sanders, J. Am. Chem. Soc., 1990, 112, 5773-5780.

112 H. L. Anderson, C. A. Hunter, M. N. Meah and J. K. M. Sanders, J. Am. Chem. Soc., 1990, 112, 5780-5789.

113 S. S. Eaton and G. R. Eaton, J. Chem. Soc., Chem. Commun., 1974, 576-577.

114 R. W. Wagner, T. E. Johnson and J. S. Lindsey, J. Am. Chem. Soc., 1996, 118, 11166-11180.
115 S. S. Eaton and G. R. Eaton, J. Am. Chem. Soc., 1975, 97, 3660-3666.

116 R. Dennington, T. Keith and J. Millam, GaussView, Version 5.0.9, Semichem Inc., Shawnee Mission, KS, 2009.

117 G. Ercolani and L. Schiaffino, Angew. Chem., Int. Ed., 2011, 50, 1762-1768.

118 C. A. Hunter and H. L. Anderson, Angew. Chem., Int. Ed., 2009, 48, 7488-7499.

119 H. J. Hogben, J. K. Sprafke, M. Hoffmann, M. Pawlicki and H. L. Anderson, J. Am. Chem. Soc., 2011, 133, 2096220969.

120 M. Strohalm, mMass 5.4.1, 2012 http://www.mmass.org/.

121 H. E. Gottlieb, V. Kotlyar and A. Nudelman, J. Org. Chem., 1997, 62, 7512-7515.

122 G. Sheldrick, Acta Crystallogr., Sect. A: Found. Crystallogr., 2008, 64, 112-122.

123 L. Farrugia, J. Appl. Crystallogr., 1997, 30, 565.

124 L. Farrugia, J. Appl. Crystallogr., 1999, 32, 837-838.

125 D. D. Perrin, L. Armarego and D. R. Perrin, Purification of Laboratory Chemicals, Pergamon Press, Ltd., Oxford, 1966.

126 J. G. Hill, B. E. Rossiter and K. B. Sharpless, J. Org. Chem., 1983, 48, 3607-3608.

127 D. Craig, J. Am. Chem. Soc., 1951, 73, 4889-4892.

128 G. Ercolani, C. Piguet, M. Borkovec and J. Hamacek, J. Phys. Chem. B, 2007, 111, 12195-12203. 